\title{
Passive and hybrid mitigation of potential near-fault inner pounding of a self-braking seismic isolator
}

\author{
Mohammed Ismail ${ }^{\mathrm{a}, \mathrm{b}}$, José Rodellar ${ }^{\mathrm{b}, *}$, Francesc Pozo $^{\mathrm{b}}$ \\ a Structural Engineering Department, Zagazig University, 44519 Zagazig, Egypt \\ ${ }^{\mathrm{b}}$ Department of Applied Mathematics III, Universitat Politècnica de Catalunya-BarcelonaTECH, 08034 Barcelona, Spain
}

\section{A R T I C L E I N F O}

\section{Article history:}

Received 24 November 2012

Received in revised form

17 October 2014

Accepted 25 October 2014

\section{Keywords:}

Base isolation

Roll-n-cage isolator

Near-fault earthquakes

Hybrid structural control

Pounding

Buffer mechanism

\begin{abstract}
A B S T R A C T
A seismic isolated structure is usually a long-period structural system, which may encounter a lowfrequency resonance problem when subjected to a near-fault earthquake that usually has a long-period pulse-like waveform. This long-period wave component may result in an enlargement of the base displacement and a decrease of the isolation efficiency. To overcome this problem, a rolling-based seismic isolator, referred to as roll-n-cage (RNC) isolator, has been recently proposed. The RNC isolator has a built-in buffer (braking) mechanism that limits the peak isolator displacements under severe earthquakes and prevents adjacent structural pounding. This paper addresses the problem of passive and hybrid mitigation of the potential inner pounding of the self-braking RNC isolator under near-fault earthquakes. Numerical results show that the RNC isolator can intrinsically limit the isolator displacements under near-fault earthquakes with less severe inner pounding using additional hysteretic damping and active control forces.
\end{abstract}

(c) 2014 Elsevier Ltd. All rights reserved.

\section{Introduction}

In earthquake-prone areas, civil structures experience exceptional loading conditions that may result in wide undesirable losses and damage. Seismic isolation systems are essentially designed to preserve structural safety, prevent occupants' injury and properties' damage. The major concept in base isolation is to diminish the fundamental frequency of structural vibration to a value lower than the dominant energy frequencies of earthquake ground motions [1]. However, seismically isolated structures are expected to experience large displacements relative to the ground especially under near-fault (NF) earthquakes. The NF ground motions are characterized by one or more intense long-period velocity and displacement pulses, which lead to a large isolator displacement $[2,3]$. Such large displacements are accommodated by providing a sufficient seismic gap around the isolated structure. In some cases, the width of the provided seismic gap is limited due to practical constraints. Therefore, a reasonable concern is the possibility of pounding of seismically isolated structures with the

\footnotetext{
* Correspondence to: Department of Applied Mathematics III, School of Civil Engineering, Technical University of Catalonia, Campus Nord, Module C-2, 08034 Barcelona, Spain. Tel.: +349340168 65; fax: +34934011825.

E-mail addresses: mohammed.ismail@upc.edu (M. Ismail), jose.rodellar@upc.edu (J. Rodellar), francesc.pozo@upc.edu (F. Pozo).

surrounding adjacent structures during severe seismic excitations such as NF ground motion earthquakes.

Regarding pounding, significant research works have been reported for the case of conventional buildings, like for instance [4-9], where adjacent buildings are connected through damping devices. In the context of earthquake-induced pounding of base isolated structures, in [10], the author simulated the superstructure of an isolated building as a continuous shear beam in order to investigate the effects of pounding on structural response. A very high acceleration response was observed during pounding with the surrounding retaining wall at the isolation level. Similar work was done by Malhotra [11], where it was found that the base shear forces increase with the stiffness of the isolated structure or the surrounding retaining wall. The seismic response of multi-story building supported on various base isolation systems during impact with adjacent structures was studied by Matsagar and Jangid [12]. It was observed that superstructure acceleration increases with the increase of the isolation gap up to a certain value and then the acceleration decreases with further increase of gap, and the effects of impact are found to be severe for the system with flexible superstructure, increased number of stories and greater stiffness of the adjacent structure. In [13], the earthquake induced pounding in friction varying base isolated buildings was investigated. They found that the impact force is very high when the sliding friction coefficient is constant. However, the impact force is quite low when the friction coefficient is allowed to vary 
a

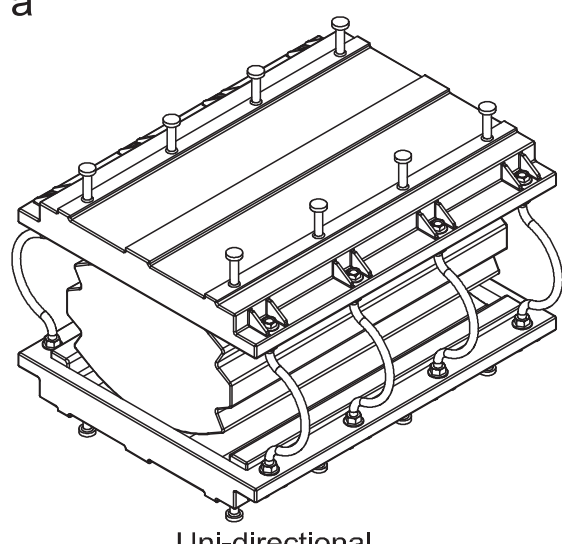

b

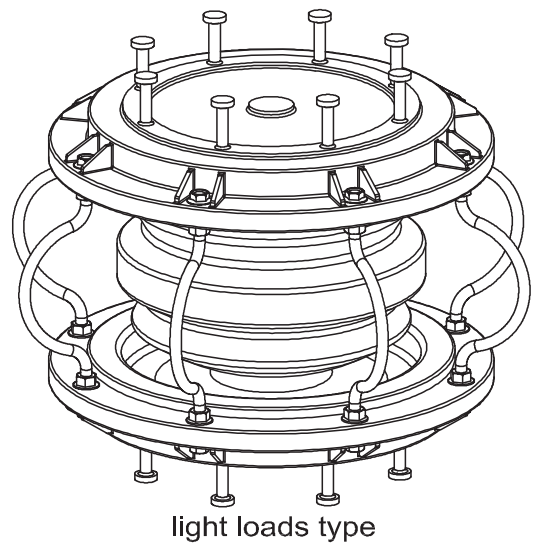

C

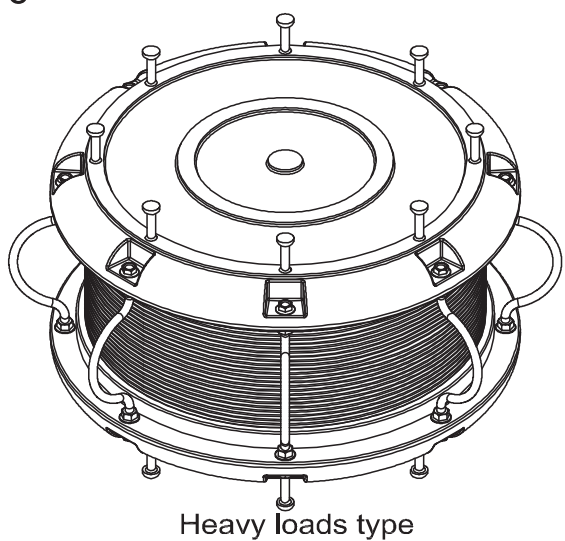

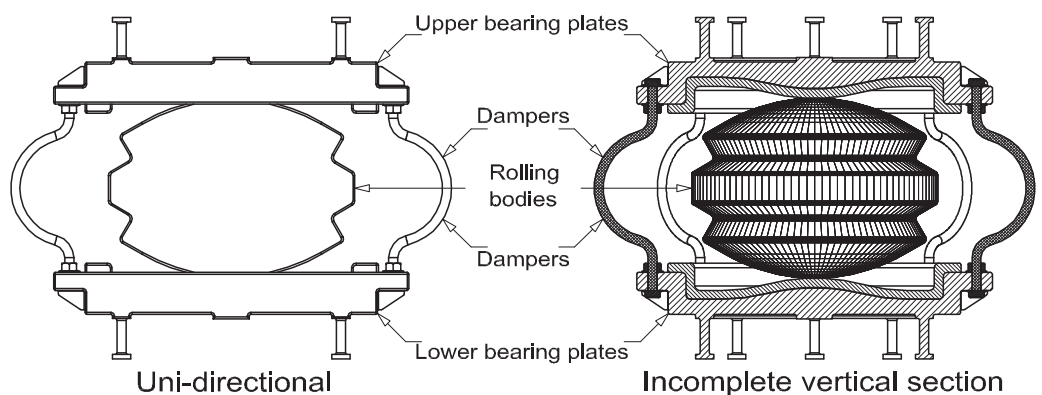

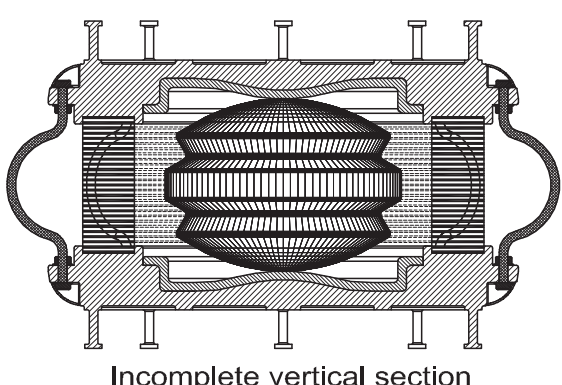

Fig. 1. The available forms of the RNC isolator : (a) unidirectional; (b) multidirectional for light to moderate structures; (c) multidirectional for heavy structures.

with velocity. Through parametric analysis, Komodromos et al. studied the effects of pounding of a seismically isolated building with the surrounding retaining wall $[14,15]$, revealing the damaging effects of structural impact on the effectiveness of seismic isolation. The pounding of an isolated building with adjacent structures was studied in [16]. It was found that if a sufficient gap is provided, with which pounding with the surrounding moat wall at the base of the building could be avoided, this does not ensure that the building will not eventually collide with neighboring buildings due to the deformations of their superstructures.

A new seismic isolation device, called roll-n-cage (RNC) isolator, has been recently proposed in [17-20]. Fig. 1 illustrates three possible typical configurations, where essentially a rolling body with a special quasi-elliptical geometry is nested between two upper and lower plates. The RNC isolator provides in a single unit all the necessary functions of rigid support, horizontal flexibility with enhanced stability and energy dissipation characteristics, in addition to an integrated buffer mechanism. This mechanism is built by a proper geometric design of the rolling body and the lower and upper plates, as shown in Fig. 2. The two main advantages of incorporating the buffer mechanism into the RNC isolator are as follows:

1. To limit the base displacement under severe earthquakes stronger than the design earthquake. This helps avoiding large unrecoverable base displacements.

2. To restrict the potential pounding (if any), under severe earthquakes, within the RNC isolator bounds. This aims to keep the adjacent structural pounding away from happening in order to minimize or even avoid the very likely damage due to structural pounding.

The above second advantage may require the price of internal shocks between parts of the isolator, see Fig. 2. This paper is concerned with analyzing and mitigating the severity of such

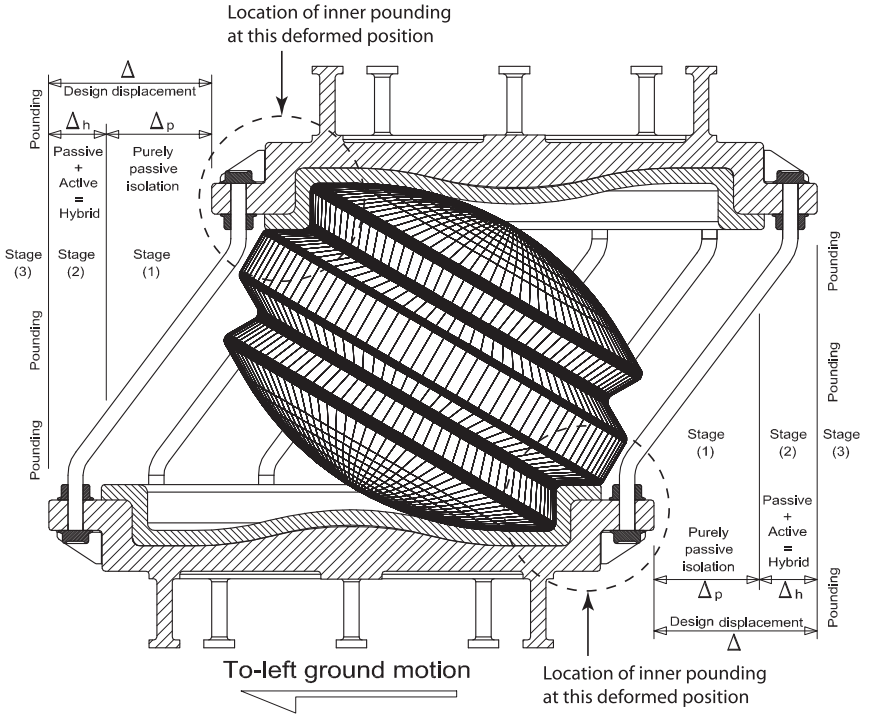

Fig. 2. The integrated buffer mechanism of the RNC isolator.

shocks and investigating their influence in the effectiveness of the RNC device for achieving a satisfactory structural isolation.

The approach proposed in this paper for reducing the internal pounding is twofold: first, by using purely passive means, and second by adding feedback active control forces. In the passive mode, the paper investigates the ability of the provided damping mechanism of the isolator, by means of metallic hysteretic dampers arranged around the rolling body as seen in Fig. 1, to reduce the bearing displacement to be within affordable limits to avoid pounding. In the active mode, the paper proposes the application of a supplementary active force to control (reduce) the isolated base displacement just before attaining the design bearing displacement ( $\Delta$ in Fig. 2 ) to reduce the possibility of pounding and its effect on 
the isolated superstructure. Two control laws are studied, both using velocity feedback since velocity is directly related to the kinetic energy, which governs the degree of pounding severity.

Combinations of passive base isolators and feedback controllers (applying active or semi-active forces) have been proposed in recent years [21-27]. The basic conceptual idea behind these hybrid schemes is that, although a base isolator can reduce by itself both the inter-story drift and the structural accelerations if it is well designed, significant base displacements may happen, particularly under sever of near-fault ground motions. The role of feedback control is to introduce supplementary forces to control such large base displacements. In the same vein, in this paper, hybrid combination of passive and active control is investigated to benefit from the unique features of RNC isolation concept while limiting potential inner pounding.

The paper is written incorporating the different elements of the study in a constructive manner. In Section 2 several near-fault ground motions are defined, which are used for numerical testing. Section 3 describes the case study building and gives the details of the RNC devices used for the seismic isolation. Section 4 is devoted to the passive solution to the pounding problem, where the influence of the hysteric dampers is studied. The hybrid solution is developed in Section 5. In both Sections 4 and 5, extensive numerical studies are performed to demonstrate an effective compromise in reducing the bearing displacements (internal pounding) while ensuring isolation efficiency in terms of peak structural absolute accelerations. Conclusions and practical issues derived from the study are given in Section 6.

\section{Near-fault ground motions}

NF ground motions are characterized by one or more intense long-period velocity and displacement pulses that can lead to a large isolator displacement [2,3]. Therefore, five NF ground motions of different intensities and various velocity and displacement pulses are considered to assess the performance of the RNC isolator damping and buffer mechanisms. These NF ground motions were obtained from the near-most station to the fault rupture, with intensities that range from $0.27 \mathrm{~g}$ to $1.23 \mathrm{~g}$ to represent small to severe intensity earthquakes. The peak ground accelerations (PGA), velocities (PGV) and displacements (PGD) against their corresponding time instants of each ground motion are listed in Table 1. The measurement of the intensity of NF ground motions by Makris and Black [28] revealed that the peak ground acceleration is a better representative intensity measure than the peak ground velocity. Accordingly, the used NF ground motions are sorted by their PGA in an ascending order.

\section{Modeling of RNC isolator}

The RNC isolator is a recently proposed seismic isolator [17-19], see Fig. 1. Its motion mechanism is rolling-based to achieve minimal structure-ground or superstructure-substructure coupling in horizontal direction. The unique configuration of the rolling body provides a built-in linear gravity-based recentering mechanism and an energy absorbing braking mechanism (buffer) with the help of hyperelastic pads that cover the inner faces of upper and lower bearing plates. Vibration damping takes place through a series of metallic hysteretic dampers arranged around the rolling body with certain shape, see Fig. 1. The shape of the metallic yield dampers was chosen to provide adequate length for extension during motion, reduce stress concentrations at bends and to force the dampers to deform away from the rolling body, therefore, they never touch each other. The RNC isolator generates no vertical acceleration components out from the horizontal ground motions due to the carefully designed curvatures of the inner faces of upper and lower bearing plates. Those curvatures absorb exactly the gradually developed uplift that results in rolling of the quasi-ellipsoidal rolling body keeping the same vertical offset between lower-most and uppermost surfaces of the RNC isolator. More detailed description and thorough treatment of the RNC isolator is found in [29].

The restoring force of the RNC isolator, $F_{\mathrm{b}}$, is of hysteretic nature, $[18,19]$, and it has three main components:

1. Hysteretic component, $F_{\mathrm{bH}}$.

2. Recentering component, $F_{\mathrm{bR}}$.

3. Buffer component, $F_{\mathrm{bB}}$.

\subsection{Hysteretic restoring component of RNC isolator}

First, the hysteretic component, $F_{\mathrm{bH}}$, is related to the metallic yield dampers, which represent the main source of energy dissipation, Fig. 3(a). It is defined as the sum of the horizontal components $\sum_{i=1}^{n d} F_{\mathrm{dh}}$ of the damper force $F_{\mathrm{d}}$, where $n d$ is the number of dampers, see Fig. $3(\mathrm{~b})$. This hysteretic component, $F_{\mathrm{bH}}$, is adequately simulated mathematically by the standard form of the Bouc-Wen model of smooth hysteresis [30,31] as

$F_{\mathrm{bH}}=\alpha k x+(1-\alpha) D_{\mathrm{y}} k z$

$\dot{z}=D_{\mathrm{y}}^{-1}\left(A \dot{x}-\beta|\dot{x}||z|^{n-1} z-\gamma \dot{x}|z|^{n}\right)$

where $x$ is the displacement, $z$ is an auxiliary variable, $F_{\mathrm{bH}}$ is the isolator restoring force due to hysteretic yield dampers, $\alpha k x$ is the elastic force component, $\dot{z}$ denotes the time derivative, $n>1$ is a parameter that governs the smoothness of the transition from elastic to plastic response (yielding exponent), $D_{\mathrm{y}}>0$ is the yield constant displacement and $0<\alpha<1$ represents the post- to preyielding stiffness ratio $\left(k_{\mathrm{p}} / k_{\mathrm{e}}\right)$, while $A, \beta$ and $\gamma$ are nondimensional parameters that govern the shape and size of the hysteresis loop.

\subsection{Recentering restoring component of RNC isolator}

The second component of the restoring force, $F_{\mathrm{bR}}$, is due to the quasi-ellipsoidal configuration of the rolling body (core) that

Table 1

Main characteristics of the NF ground motions used in this study.

\begin{tabular}{|c|c|c|c|c|c|c|c|c|c|c|c|}
\hline \multirow[t]{2}{*}{ No. } & \multirow[t]{2}{*}{ Earthquake name } & \multirow[t]{2}{*}{ Year } & \multirow[t]{2}{*}{ Station name } & \multirow[t]{2}{*}{ Magnitude } & \multirow[t]{2}{*}{ Distance to fault (km) } & \multicolumn{2}{|c|}{ Peak accel. (g) } & \multicolumn{2}{|c|}{ Peak vel. $(\mathrm{cm} / \mathrm{s})$} & \multicolumn{2}{|c|}{ Peak disp. (cm) } \\
\hline & & & & & & PGA & Time & PGV & Time & PGD & Time \\
\hline 1 & Kocaeli, Turkey $60^{\circ}$ & 1999 & Yarimca & 7.51 & 4.80 & 0.27 & 13.84 & 67.0 & 13.57 & 58.2 & 14.75 \\
\hline 2 & Imperial Valley $230^{\circ}$ & 1979 & El Centro Ar. \#7 & 6.53 & 0.60 & 0.46 & 5.00 & 111.4 & 5.94 & 45.6 & 6.85 \\
\hline 3 & Kobe, Japan $0^{\circ}$ & 1995 & Takarazuka & 6.90 & 0.30 & 0.69 & 6.02 & 69.9 & 6.58 & 27.2 & 6.02 \\
\hline 4 & Northridge $18^{\circ}$ & 1994 & Sylmar - Conv. SE & 6.69 & 5.20 & 0.83 & 3.51 & 119.8 & 3.44 & 35.1 & 3.02 \\
\hline 5 & San Fernando $164^{\circ}$ & 1971 & Pacoima Dam & 6.61 & 1.80 & 1.23 & 7.76 & 114.7 & 3.07 & 36.1 & 7.81 \\
\hline
\end{tabular}


provides the RNC isolator with a linear built-in gravity-based recentering mechanism as shown in Fig. 4. The intention beyond the integration of such mechanism is to prevent having residual displacements after the earthquake and also to help reducing the peak isolator's displacement. The eccentricity provided by the quasi-ellipsoidal configuration together with the downward structural weight $W_{\mathrm{s}}$ and the upward reaction $R$ form a restoring

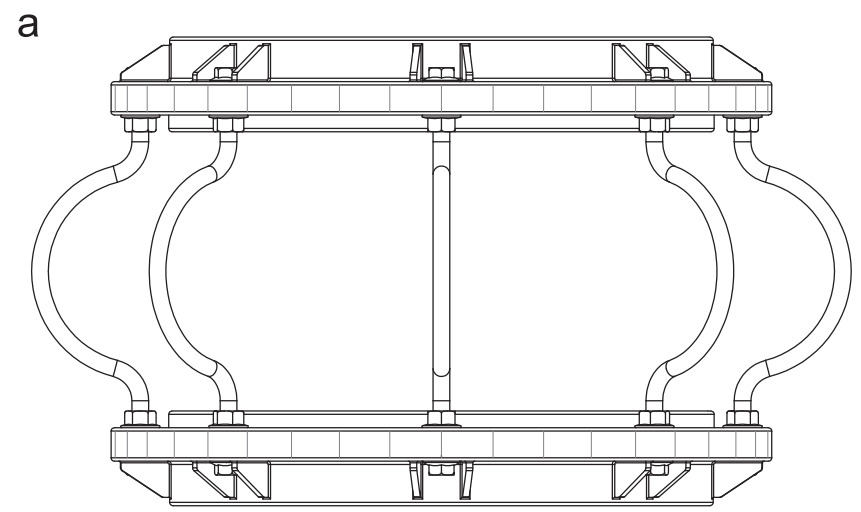

$\mathrm{b}$
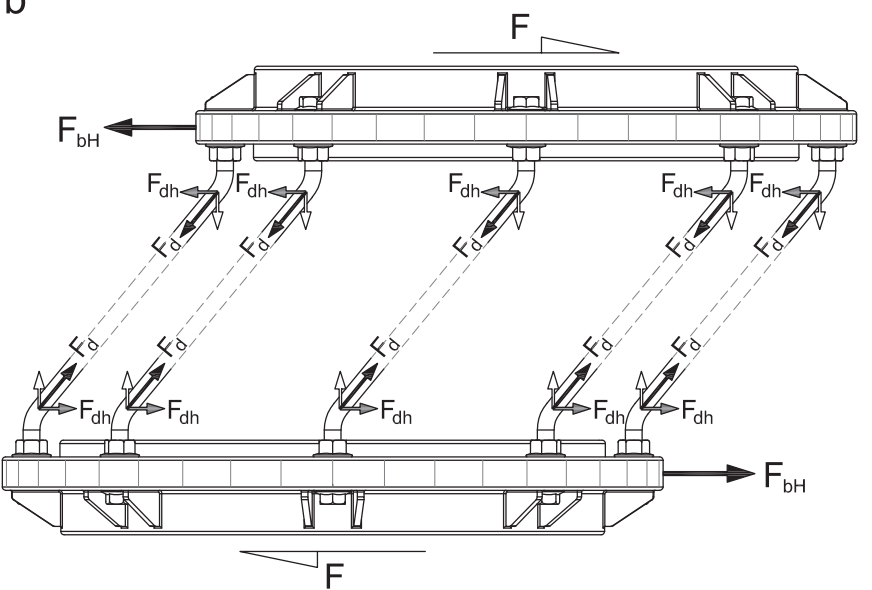

Fig. 3. The hysteretic restoring mechanism of the RNC isolator: (a) neutral position; (b) deformed position. couple $M_{\text {res }}$ opposite to the rotating couple as illustrated in Fig. 4(a) and (c).

According to the available literature, elliptically shaped supports have two main drawbacks: (1) the supported structure vibrates as a simple pendulum having a unique vibration period, which causes resonance if it is close to the dominant period of the exciting earthquake. (2) They suffer an increasing vertical uplift as they move horizontally, as shown in Fig. 5(a) and (b). This generates undesired vertical acceleration component from the horizontal motion component, which may cause discomfort to occupants besides being harmful to motion-sensitive inner equipment.

The quasi-ellipsoidal RNC isolator was designed to eliminate the above drawbacks as it exhibits no vertical uplift during motion and has no fixed vibration period, while maintaining the advantage of eccentricity. This is attributed to the carefully designed curvatures of the inner faces, facing the rolling core, of the upper and lower bearing plates, as shown in Fig. 6. Such curvatures absorb the gradually increasing uplift that develops as a result of the quasi-ellipsoidal core rolling. Therefore, the RNC isolator rolls as a sphere with no vertical uplift nor fixed vibration period. This means that no resistance to motion will be developed nor needed to raise the supported structure, keeping nearly the same degree of structure-ground decoupling along the excitation time history.

To mathematically express the restoring force, $F_{\mathrm{bR}}$, let us consider a unidirectional horizontal motion of the RNC isolator along the $x$-axis. As shown in Fig. 5 the rolling surfaces of the RNC isolator quasi-elliptical core fit perfectly with an ellipse having a major horizontal axis of length $2 a$ and a minor vertical axis of length $2 b$, Fig. 5(a). The eccentricity of the elliptical core is expressed as

$e=\sqrt{\frac{a^{2}-b^{2}}{a^{2}}}$.

Consider Fig. 5(a) and (b) where the elliptical rolling body is in rolled position between flat base mass and flat foundation. The motion is characterized by the following variables:

$x_{\mathrm{r}}=\frac{x_{\mathrm{b}}}{2}$,

$$
y_{\mathrm{r}}=p-b,
$$

a

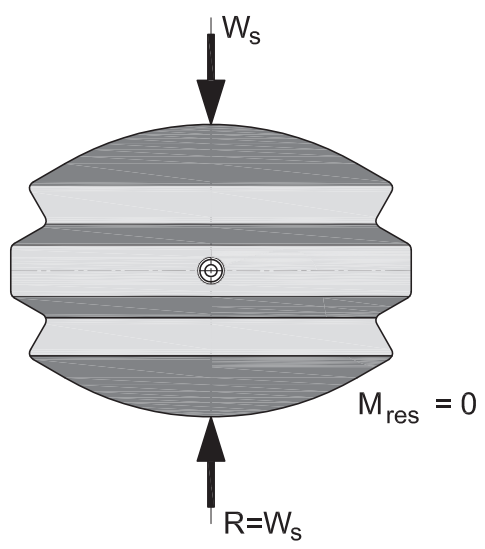

Neutral position zero rotating couple b

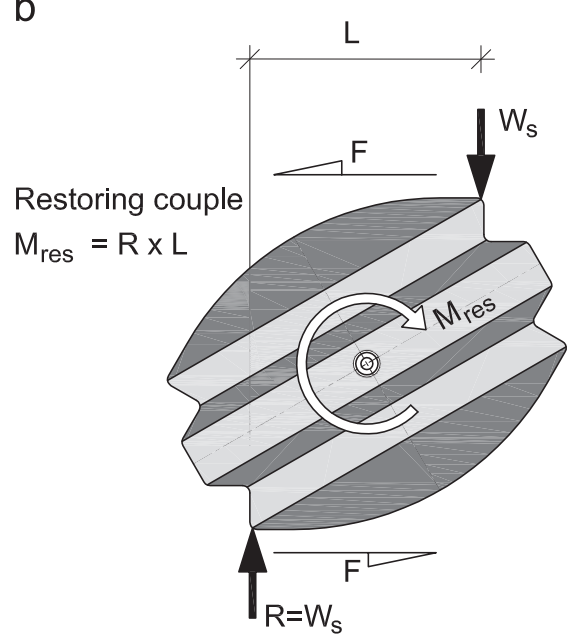

Counterclockwise rotating couple

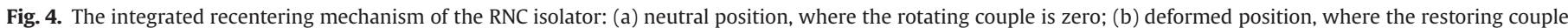
develops due to the generated eccentricity. 
a

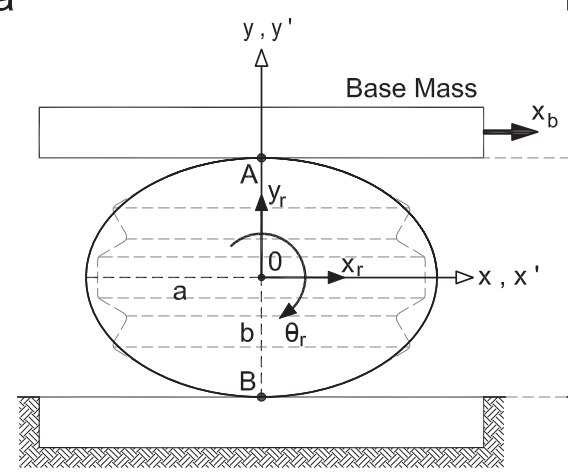

Foundation b

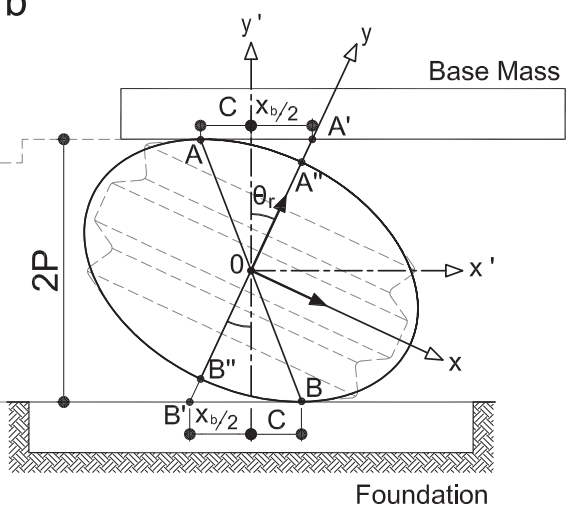

C

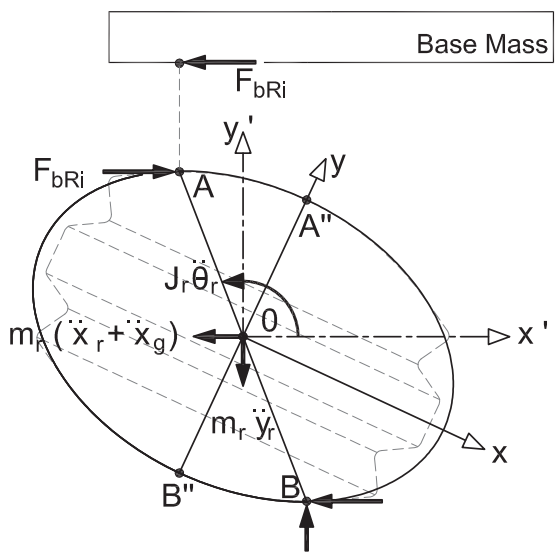

d

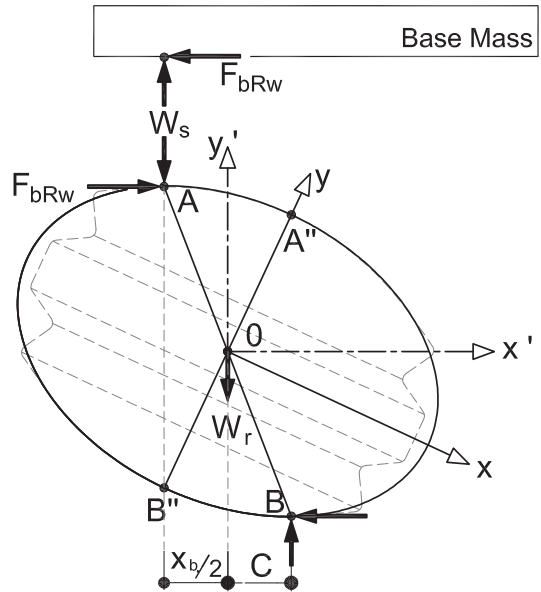

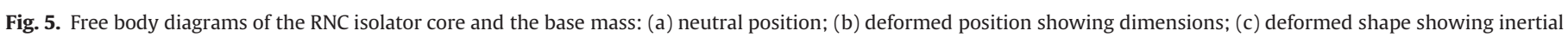
forces; (d) deformed shape showing weights.

$\theta_{\mathrm{r}}=\tan ^{-1}\left(\frac{b}{a} \tan \theta\right)$

where $x_{\mathrm{r}}$ and $y_{\mathrm{r}}$ are the horizontal and vertical displacements of the center of gravity (CG) relative to ground, respectively; $\theta_{\mathrm{r}}$ is the rotation angle of the rolling body; $x_{\mathrm{b}}$ is the horizontal displacement of the isolator or the base mass relative to the ground; $p=a \sin \theta \sin \theta_{\mathrm{r}}+b \cos \theta \cos \theta_{\mathrm{r}} \quad$ is half the vertical distance between the lower and upper contact points [points $A$ and $B$ in Fig. 5(a) and (b)] of the rolling core; $\theta$ is the eccentric angle such that the coordinates of point $A$ are $(-a \sin \theta, b \cos \theta)$ and hence the distance $O A=\sqrt{a^{2} \sin ^{2} \theta+b^{2} \cos ^{2} \theta}=a \sqrt{1-e^{2} \cos ^{2} \theta}$.

By equating the distances $A A^{\prime}$ and $A A^{\prime \prime}$ in Fig. 5(b), a relation between the eccentric angle $\theta$ and the base displacement $x_{\mathrm{b}}$ can be expressed as

$\frac{x_{\mathrm{b}}}{2}+c=a \int_{0}^{\theta} \sqrt{1-e^{2} \cos ^{2} \phi} d \phi$,

where $c=a \sin \theta \cos \theta_{\mathrm{r}}-b \cos \theta \sin \theta_{\mathrm{r}}$ is half the horizontal distance between the upper and lower contact points. Note that the right hand side of Eq. (7) contains a special function known as an elliptic integral of the second kind. The value of this integral is available in standard charts and tables [32] knowing $e$ and $\theta$. Eq. (7) gives a design tool for the rolling body geometry. For a given value of $e$ and $\theta$, Eq. (7) allows us to calculate the corresponding horizontal base displacement $x_{\mathrm{b}}$. In this study, for a particular value of the base displacement, $x_{\mathrm{b}}$, the value of $\theta$ is obtained by trial and error along with the use of standard tables.
The total horizontal recentering restoring force of the RNC isolator, $F_{\mathrm{bR}}$, may be described as if composed of two components: (1) inertial component, $F_{\mathrm{bRi}}$, which is the force transmitted to the base mass due to the inertia forces of the isolator core and (2) gravitational component, $F_{\mathrm{bRw}}$, which is a result of the developed eccentricity between the vertical lines of actions of the downward structural weight $W_{\mathrm{s}}$, isolator rolling core weight $W_{\mathrm{r}}$ and their upward reactions. This can be mathematically expressed as

$F_{\mathrm{bR}}=F_{\mathrm{bRi}}+F_{\mathrm{bRw}}$

To determine the inertial component, $F_{\mathrm{bRi}}$, let us consider the equilibrium of inertia forces acting on the rolling core, Fig. 5(c). Then, $F_{\mathrm{bRi}}$ is expressed as

$F_{\mathrm{bRi}}=\frac{1}{2 p} J_{\mathrm{r}} \ddot{\theta}_{\mathrm{r}}+m_{\mathrm{r}} \ddot{y}_{\mathrm{r}} \frac{c}{p}+\frac{1}{2} m_{\mathrm{r}}\left(\ddot{x}_{\mathrm{r}}+\ddot{x}_{\mathrm{g}}\right)$,

where $m_{\mathrm{r}}$ and $J_{\mathrm{r}}$ are the mass and the moment of inertia of the rolling body, respectively, and $\ddot{x}_{\mathrm{g}}$ is the ground acceleration.

Due to the curvatures of the inner faces of the upper and lower bearing plates (see Fig. 6) that prevent the vertical uplift of the supported structure along the whole time history of the earthquake, Eq. (5) becomes $y_{\mathrm{r}}=p-b=0$ and Eq. (9) reduces to

$F_{\mathrm{bRi}}=\frac{1}{2 p} J_{\mathrm{r}} \ddot{\theta}_{\mathrm{r}}+\frac{1}{2} m_{\mathrm{r}}\left(\ddot{x}_{\mathrm{r}}+\ddot{x}_{\mathrm{g}}\right)$

To determine the other gravitational component of the recentering force, $F_{\mathrm{bRw}}$, let us consider Fig. 5(d). By equating the moments 
a

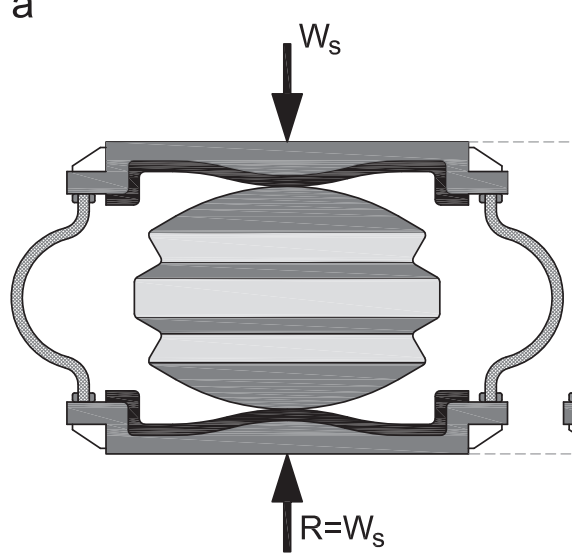

b

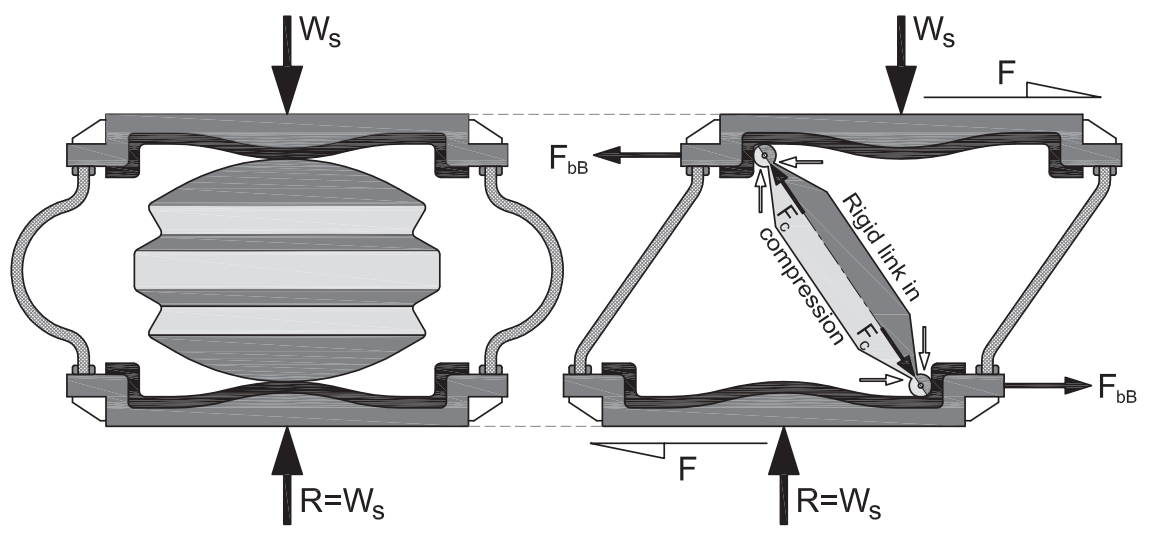

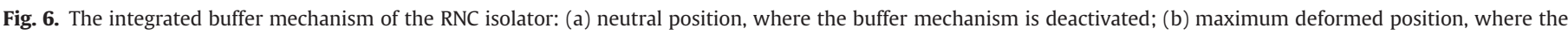
buffer mechanism is activated.

about $B$ to zero, the force $F_{\mathrm{bRw}}$ is expressed as

$F_{\mathrm{bRw}}=\frac{1}{2 p} W_{s}\left(\frac{x_{\mathrm{b}}}{2}+c\right)+\frac{1}{2 p} W_{\mathrm{r}} c$

The total recentering restoring force is then expressed in the form:

$F_{\mathrm{bR}}=\frac{1}{2 p} J_{\mathrm{r}} \ddot{\theta}_{\mathrm{r}}+\frac{1}{2} m_{\mathrm{r}}\left(\ddot{x}_{\mathrm{r}}+\ddot{x}_{\mathrm{g}}\right)+\frac{1}{2 p} W_{\mathrm{s}}\left(\frac{x_{\mathrm{b}}}{2}+c\right)+\frac{1}{2 p} W_{\mathrm{r}} c$

\subsection{Buffer restoring component of RNC isolator}

The third component of the restoring force, $F_{\mathrm{bB}}$, is attributable to the two right-angle grooves, which are cut out from the quasiellipsoidal core, together with the vertical edge-walls of the the upper and lower bearing plates, see Fig. 6. Upon reaching the maximum deformed position, a perfect lock is formed smoothly by means of those three components: the core, the upper and lower bearing plates, Fig. 6(a) and (c). At that extreme deformed condition, the RNC isolator core works as a restrained, at both ends, inclined rigid link member that allows for no more isolator motion, as shown in Fig. 6(a) and (c).

Two main objectives are beyond the integration of the buffer mechanism into the RNC isolator. The first objective is to limit the isolator displacement under extreme (low-probability) earthquakes to a previously selected design displacement, $x_{\mathrm{des}}$, as shown in Fig. 6(a) and (c). That design displacement, $x_{\text {des }}$, is normally selected to accommodate a travel distance a bit larger than that which would occur during the design earthquakes. The second target of the buffer mechanism is to prevent pounding of the isolated structure itself with the surrounding structures and to limit the possible pounding (if any) to be only within the own body of the solid RNC isolator.

To express mathematically the third component of the restoring force caused by buffer, $F_{\mathrm{bB}}$, two cases have to be considered: (1) if the isolator, or the isolated base, displacement $x_{\mathrm{b}}$ due to ground motion excitation is less than the design displacement $x_{\text {des }}$, the restoring buffer force component $F_{\mathrm{bB}}$ is set to zero and (2) if the isolator displacement exceeds the previously set design displacement $x_{\mathrm{des}}$, the buffer restoring force $F_{\mathrm{bB}}$ becomes nonzero and proportional to the buffer stiffness $k_{\mathrm{B}}$. Such nonlinear forcedisplacement relationship of the restoring buffer force component $F_{\mathrm{bB}}$ is expressed mathematically as

$F_{\mathrm{bB}}= \begin{cases}0 & \text { if }\left|x_{\mathrm{b}}\right|<x_{\text {des }} \\ k_{\mathrm{B}}\left(x_{\mathrm{b}}-x_{\text {des }}\right) & \text { if }\left|x_{\mathrm{b}}\right|>x_{\text {des }}\end{cases}$

Combining the above three components of the RNC isolator's restoring forces $F_{\mathrm{bH}}, F_{\mathrm{bR}}$ and $F_{\mathrm{bB}}$, a general expression of the overall restoring force, $F_{\mathrm{b}}$, of the RNC isolator is expressed as follows:

$F_{\mathrm{b}}= \begin{cases}F_{\mathrm{bH}}+F_{\mathrm{bR}} & \text { if }\left|x_{\mathrm{b}}\right|<x_{\mathrm{des}} \\ F_{\mathrm{bH}}+F_{\mathrm{bR}}+F_{\mathrm{bB}} & \text { if }\left|x_{\mathrm{b}}\right|>x_{\mathrm{des}}\end{cases}$

A schematic plot of the hysteretic force-displacement relationship of RNC isolator is shown in Fig. 7. It is clear that the main controlling parameters of the hysteresis loop shape are as follows:

- Yield displacement $D_{\mathrm{y}}$.

- Yield strength $F_{\mathrm{y}}$ of the hysteretic metallic yield dampers.

- Maximum restoring forces $\left(F_{\mathrm{bH}}+F_{\mathrm{bR}}\right)$ and $\left(F_{\mathrm{bH}}+F_{\mathrm{bR}}+F_{\mathrm{bB}}\right)$.

- Maximum displacement $D_{\max }$. 


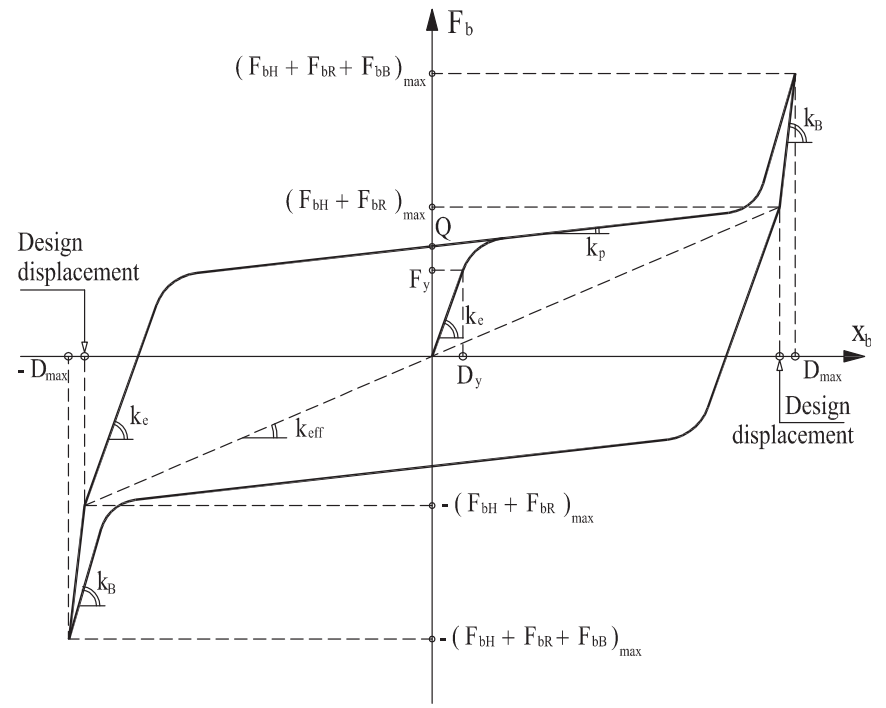

Fig. 7. Force-displacement relationship of RNC isolator.

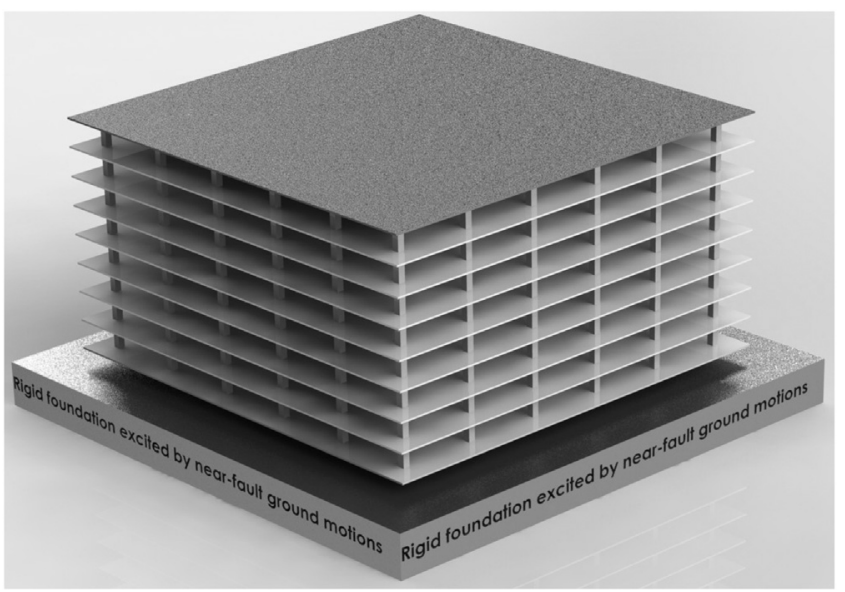

Fig. 8. 8-story RNC-isolated structure model on a rigid foundation.

- Elastic (pre-yield) stiffness $k_{\mathrm{e}}$ defined as $F_{\mathrm{y}} / D_{\mathrm{y}}$.

- Plastic (post-yield) stiffness $k_{\mathrm{p}}$.

- Effective stiffness $k_{\text {eff }}$ defined as $F_{\mathrm{b}-\max } / D_{\max }$.

- Buffer stiffness $k_{\mathrm{B}}$.

- Characteristic strength $Q$.

- The yielding exponent $n$, which controls the curvature at the hysteresis loop corners.

\section{Modeling of isolated structure}

Fig. 8 shows a schematic diagram of the RNC-isolated linear multistory structure used in this study. The structure is symmetric 3D building of 5 bays, each of $8.0 \mathrm{~m}$ span, with double end cantilevers, each of $2.5 \mathrm{~m}$ length, in each horizontal direction. It has 8 floors plus the isolated base floor with a typical story height of $3.0 \mathrm{~m}$. The base isolated structure is modeled as a shear type supported on 36 heavy-load RNC isolators, one under each column. Each floor has 2 lateral displacement degrees of freedom (DOF) beside one rotational DOF around the vertical axis. However, due to the symmetry of the 3D structure, only one horizontal displacement DOF is considered at each floor and is excited by a single horizontal component of earthquake ground motion in its direction. The superstructure is considered to remain within the elastic limit during the earthquake excitation and impact phenomenon. The construction material of the isolated structure is normal-weight reinforced concrete with a total material volume of $4068.36 \mathrm{~m}^{3}$ and the structure has a total weight of $10,170.90$ tons. The foundation of structure is assumed to be rigid and supported on rocky soil. The fixed-base structure has a fundamental period of $0.436 \mathrm{~s}$ and modal frequencies of 2.29, 6.80, 11.06, 14.94, 18.29, 21.02, 23.03 and $24.26 \mathrm{~Hz}$ for modes from one to eight, respectively. The structural damping ratio for all modes is fixed to $2.50 \%$ of the critical damping.

The RNC isolator may have three main forms as shown in Fig. 1. In this study, the heavy loads form shown in Fig. 1(c) is used to safely support the heavy column reactions. The designed RNC isolator for this study is $1.45 \mathrm{~m}$ high. The outer diameter of the upper and lower bearing steel plates is $2.73 \mathrm{~m}$. It is provided with 8 hysteretic mild steel dampers of the shape shown in Fig. 1, each has a diameter of $5.0 \mathrm{~cm}$. This RNC isolator design allows for a horizontal design displacement $\Delta$ of $53.0 \mathrm{~cm}$, after which the integrated buffer stops the motion through impact within the lock mechanism shown in Fig. 2. As shown in Fig. 1(c), the heavy load form of the RNC isolator is provided with a hollow elastomeric cylinder around the rolling body to represent the main load carrying capacity, while the rolling body itself works as a secondary support in this case. The inner and outer diameters of the hollow elastomeric cylinder are $1.73 \mathrm{~m}$ and $2.33 \mathrm{~m}$, respectively. This elastomeric part was initially designed to follow some available recommendations of the Uniform Building Code [33] and AASHTO [34]. At the end, the designed RNC isolator for this study can support up to $4000.0 \mathrm{kN}$ vertically.

The buffer mechanism of the RNC isolator is self-activated if the peak lateral displacement of the device exceeds a chosen design displacement for the device by the designer. In other respects, the buffer mechanism is not activated. To demonstrate graphically the total restoring force, $F_{\mathrm{b}}$, of the RNC isolator considering selfactivating and/or deactivating its buffer mechanism, two RNC isolators having design displacements, $x_{\text {des }}$, of $300 \mathrm{~mm}$ and $500 \mathrm{~mm}$ were designed. The RNC-isolated superstructure is then excited by the Northridge ground motion considering the two designed isolators separately. The outputs are plotted in Figs. 9 and 10 considering the two cases of buffer activation ( $x_{\text {des }}=300 \mathrm{~mm}$ ) and buffer deactivation $\left(x_{\text {des }}=500 \mathrm{~mm}\right)$, respectively. In Fig. 9(a) and (d), the peak isolator displacement exceeded the design displacement of $300 \mathrm{~mm}$ of the first RNC isolator at certain time instants. Therefore, the buffer mechanism was activated automatically showing two shocks, one in each side, along the excitation time history as shown in Fig. 9(e). The addition of Fig. 9(b) and (e) against the isolator shear displacement Fig. 9(a) or (d) forms the total restoring force-displacement relationship of the RNC isolator in this case as in Fig. 9(c). It is clear that just after exceeding the design displacement of the isolator, the force increases significantly with a slight increase in displacement, which depends mainly on the buffer stiffness, $k_{\mathrm{B}}$. Considering the other case by using the RNC isolator with having design displacement of $500 \mathrm{~mm}$ under the Northridge earthquake, the peak isolator displacement was found below the chosen design displacement, as demonstrated in Fig. 10(a) and (d). Therefore, the buffer mechanism was not activated. As a result, no shocks were developed, as shown in Fig. 10(e). This means that the total restoring force-displacement relationship, shown in Fig. 10(c), is smooth hysteretic loops as a result of zero buffer pounding forces, Fig. 10(e).

\section{Passive mode: inherent hysteretic damping}

The RNC isolator is provided with a set of triple-curvature metallic yield dampers as shown in Fig. 1, which render the device a hysteretic behavior $[18,19]$. Such curvatures are designed to allow for smooth extension and contraction of dampers during 

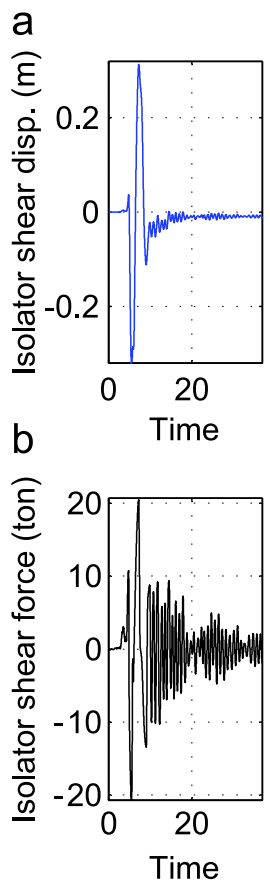

C

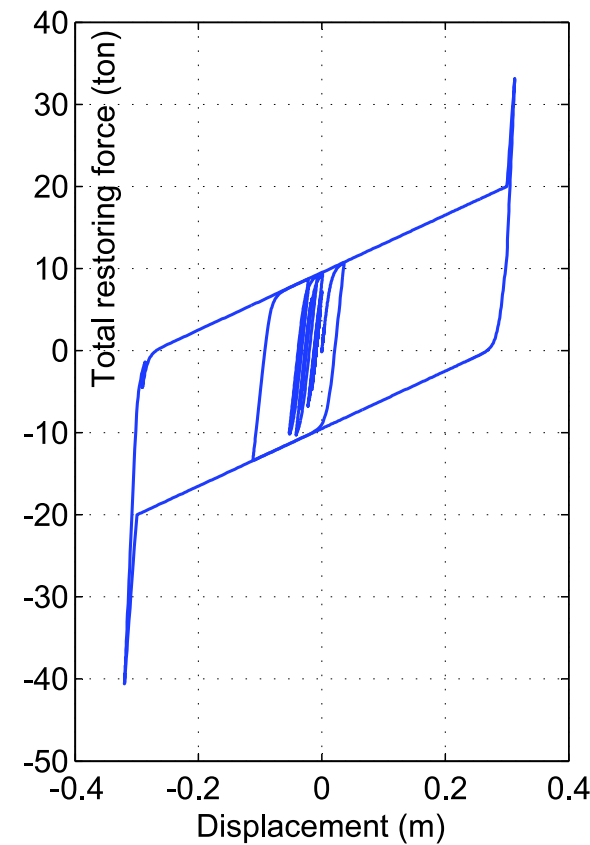

d
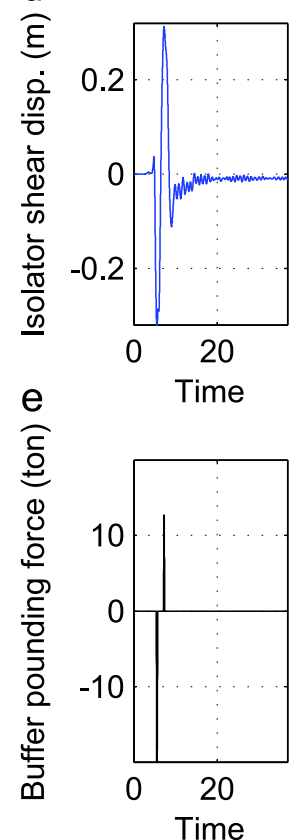

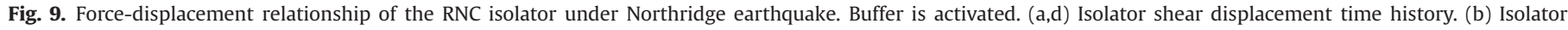
horizontal shear force time history. (c) Total restoring force-displacement relationship. (e) Buffer pounding force time history.
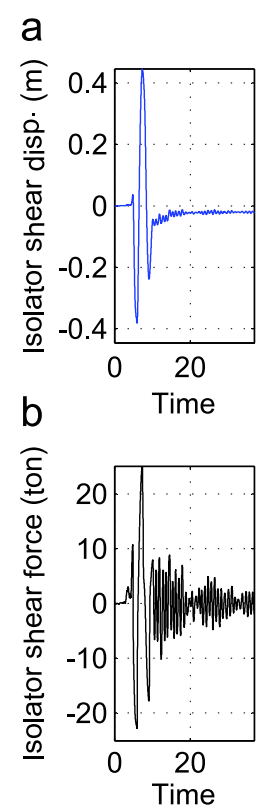

C

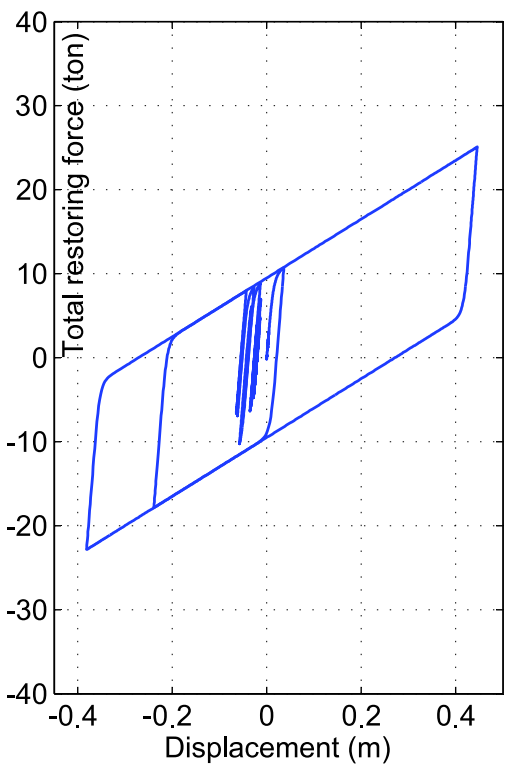

d
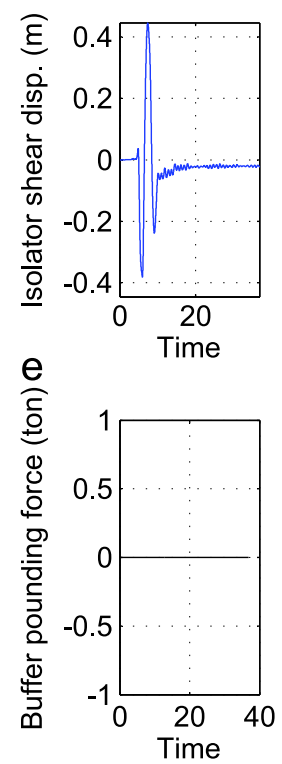

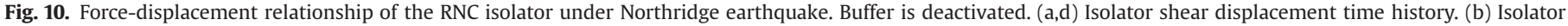
horizontal shear force time history. (c) Total restoring force-displacement relationship. (e) Buffer pounding force time history.

motion, provide adequate length of dampers to allow unrestrained rolling motion of the rolling body up to the buffer and to reduce or avoid stress concentrations at bends in order to increase the dampers working life. In order to estimate the effective damping provided by the RNC isolator used in this study, the isolator is modeled using the finite element analysis software ADINA [35]. Then it is subjected to cyclic horizontal shear displacement at different shear strain amplitudes up to $100 \%$ at loading frequency of $1 \mathrm{~Hz}$. The resulting shear force-displacement relationship is plotted against the shear strain amplitudes in Fig. 11. From these hysteresis loops, the effective damping $\xi$ of the RNC isolator were calculated using the following relationship:

$\xi=\frac{A_{\text {loop }}}{2 \pi F_{\max } d_{\max }} \eta$

where $F_{\max }$ is the peak value of the shear force, $d_{\max }$ is the peak value of the shear displacement, $A_{\text {loop }}$ is the hysteresis loop area, and $\eta$ is a factor depending on the chosen number of metallic yield dampers.

Eq. (15) is provided by Ref. [36] for hysteretic seismic isolation systems similar to the RNC isolator, but after neglecting the resulting pounding peaks due to buffer activation. Based on a 


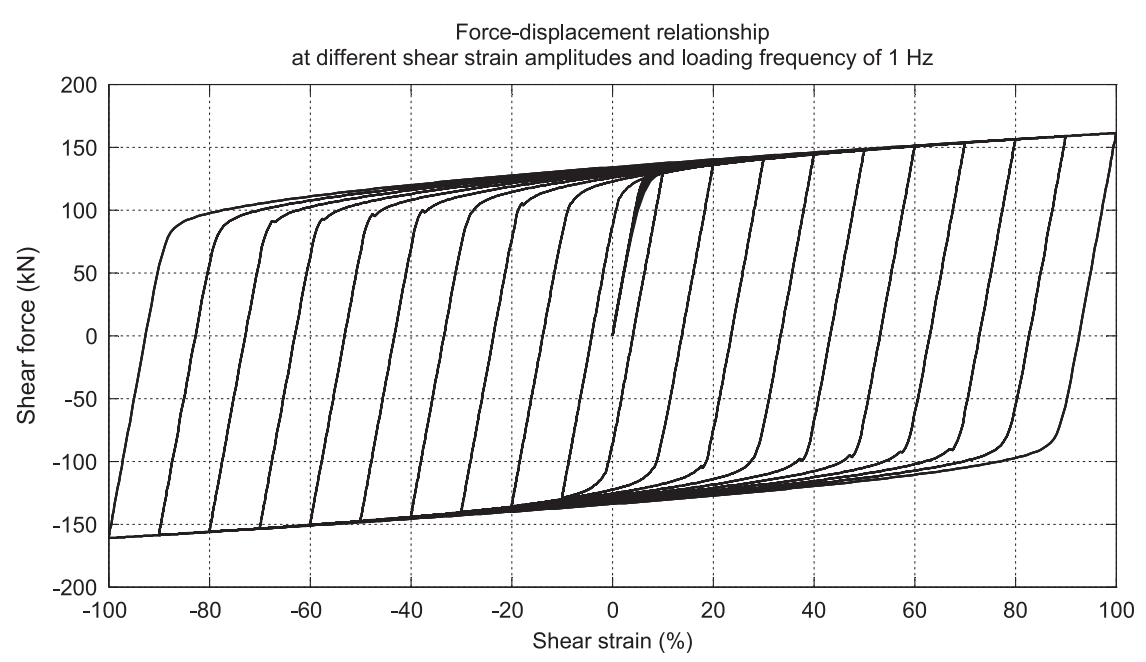

Fig. 11. The force-displacement relationship of the RNC isolator at different shear strain amplitudes.

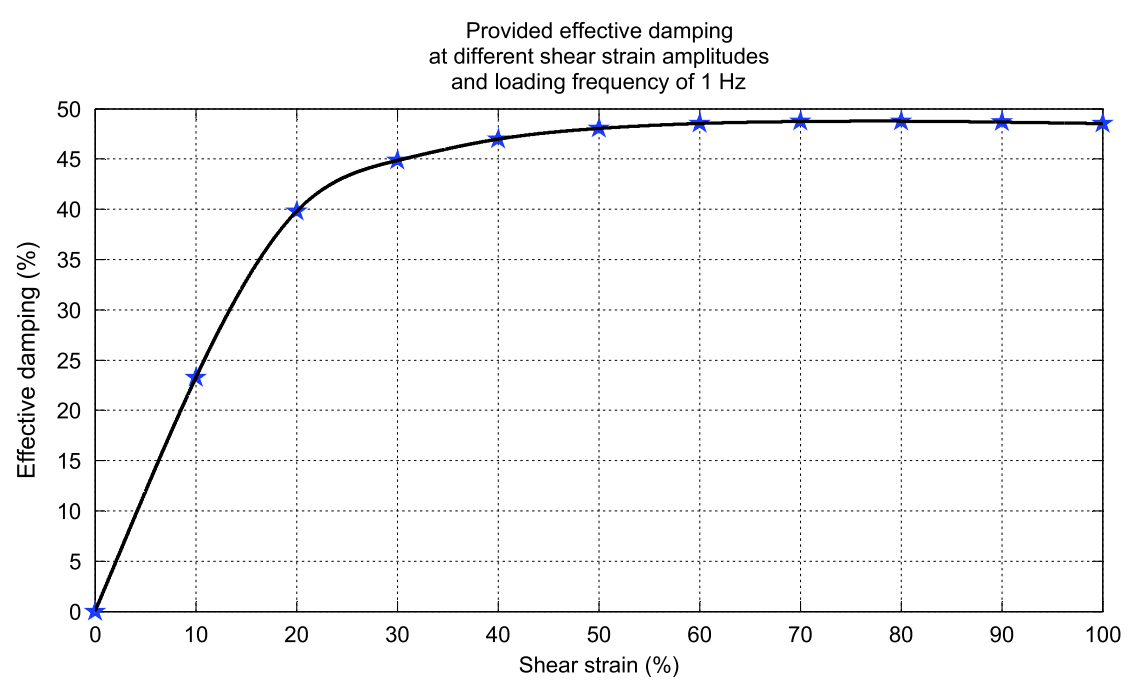

Fig. 12. RNC isolator damping vs shear strain.

profound analytical and numerical simulation studies, such equation is modified in this paper by introducing the factor $\eta$ to account for the number of metallic yield dampers, which are the main source of stiffness and damping in the RNC isolator.

The damping ratio is plotted as a function of the shear strain in Fig. 12, where the damping ratio goes up rapidly to a relatively high value of $48.76 \%$ then remains almost constant as the shear strain increases. In this section, the possibility of this high damping ratio, provided by the low-cost metallic yield dampers, to limit the bearing displacement to be within affordable limits is investigated under the NF earthquakes of Section 2.

Three structures are employed in the parametric study performed in this section: the one described in Section 4; the same structure but one time is $25 \%$ lighter in weight and the other time is $25 \%$ heavier. This to investigate the influence of the isolated structural weight on bearing displacement and pounding intensity. On the other hand, to investigate the influence of the provided amount of hysteretic damping by the RNC isolator on the bearing displacement and consequently on pounding, four designs of the RNC isolator of the form mentioned in Section 4 are considered. These four isolator designs provide different amount of hysteretic damping that, relatively, ranges from low to high damping and referred to as RNC-1, RNC-2, RNC-3 and RNC-4, respectively. They provide damping ratios of $10 \%, 20 \%, 30 \%$ and $40 \%$, respectively. Then, all the RNC-isolated structures are subjected to the five earthquakes of Section 2, one at a time, and the resulting bearing displacements as well as the pounding forces are displayed in Fig. 13. Each earthquake is referred to by its serial number found in the first column from left of Table 1 . All the response quantities in this section are obtained by simulating the RNC-isolated structures using the structural finite element software SAP2000 [37] together with MAtLAB [38]. The RNC isolator is modeled by activating the Plastic-Wen hysteretic element, where the buffer mechanism is represented by a nonlinear gap element. The structure floors were modeled as rigid horizontal diaphragms while the columns are modeled with zero axial deformation and the structural mass is lumped at floor levels.

The bearing displacements of RNC isolators RNC-1, RNC-2, RNC-3 and RNC-4 are displayed in Fig. 13(a), (b), (e), and (f), respectively. The corresponding pounding forces are shown in Fig. 13(c), (d), (g), and $(\mathrm{h})$, respectively. It seems evident that increasing the isolator hysteretic damping produces a decrease in the bearing displacement and consequently alleviates the pounding intensity, although the heavier isolated structures are less responsive to increasing the 
a
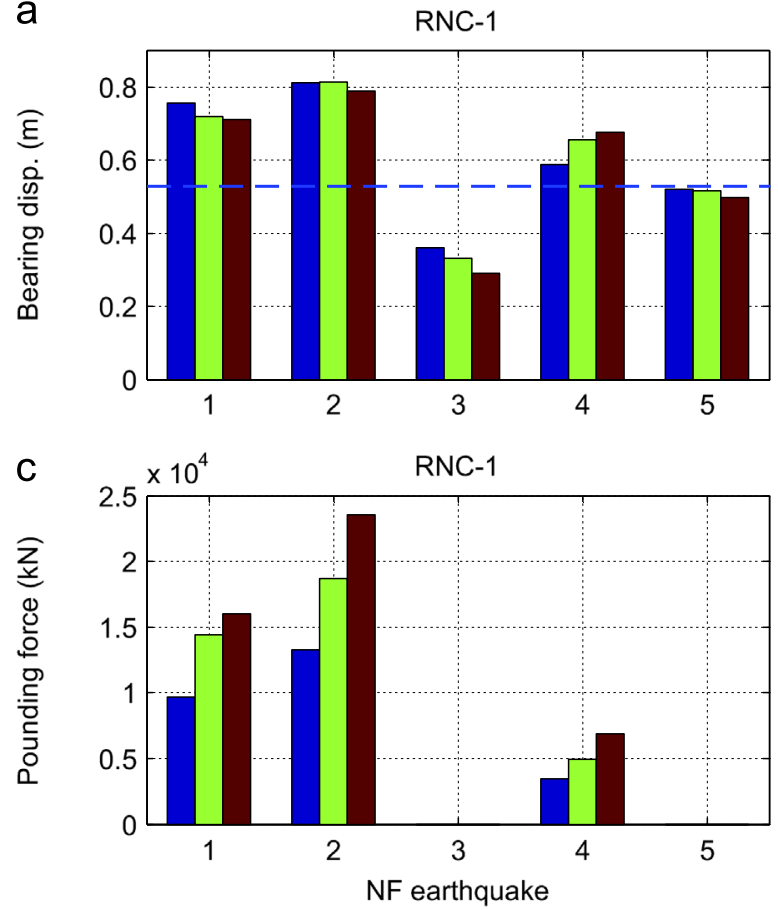

e
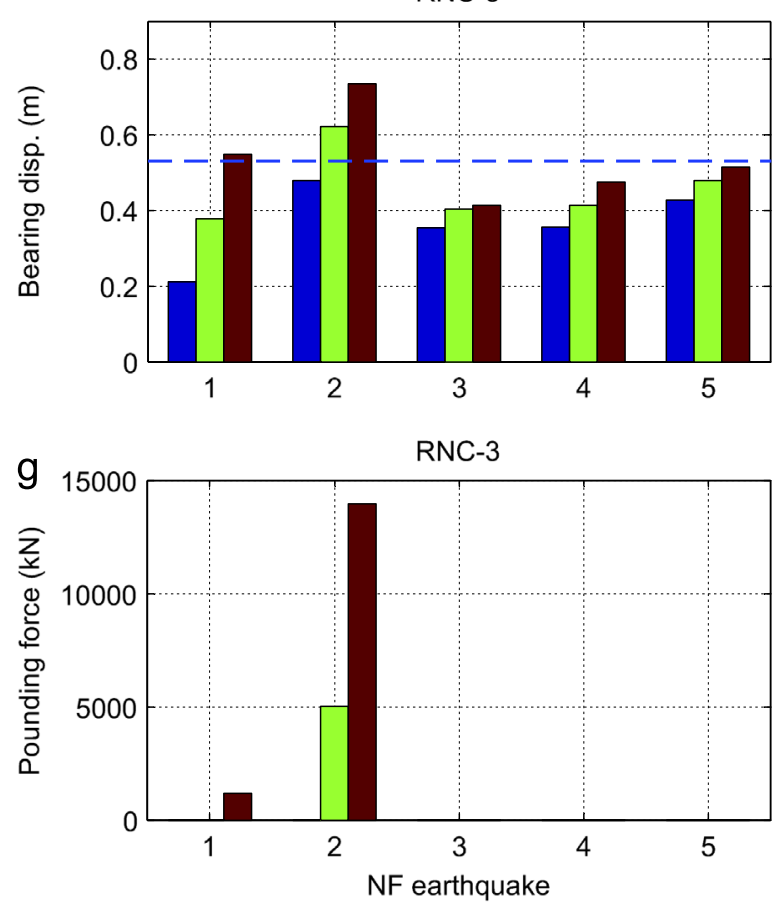

b

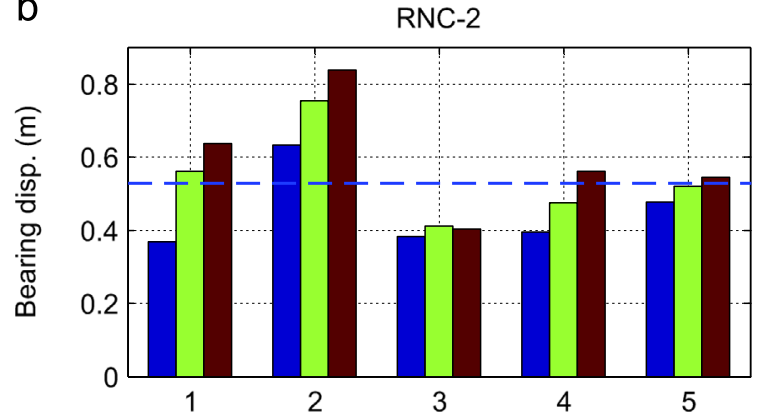

d

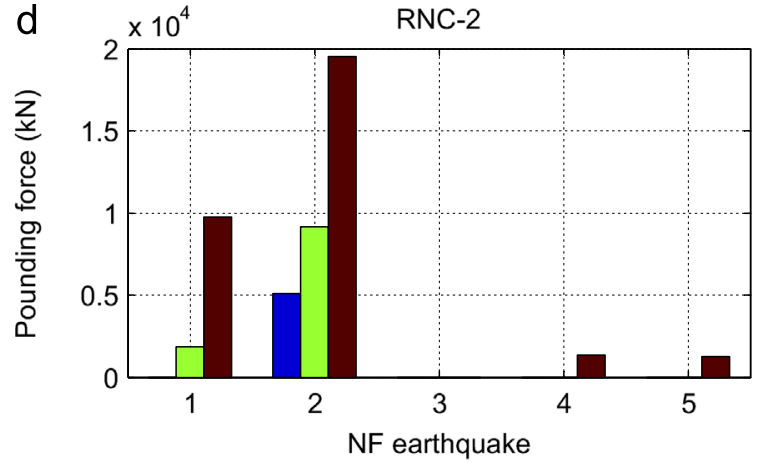

$f$
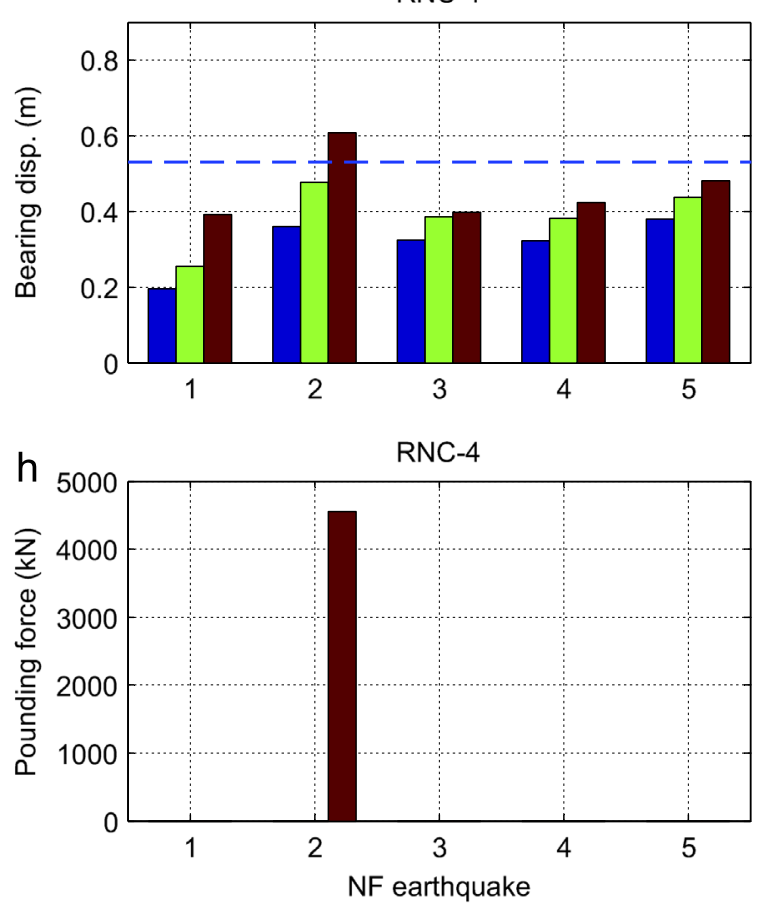

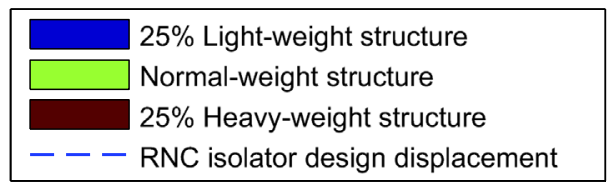

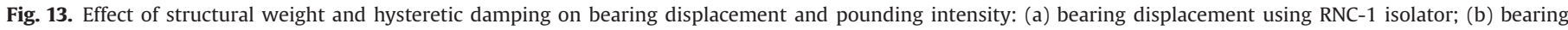

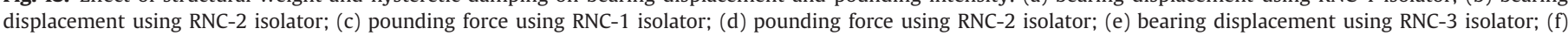
bearing displacement using RNC-4 isolator; (g) pounding force using RNC-3 isolator; and (g) pounding force using RNC-4 isolator.

isolator hysteretic damping. Fig. 13 also demonstrates that pounding is always more intense in the case of isolated heavy structures, even if they exhibit closer bearing displacements to those of isolated lighter structures. Moreover, the pounding intensity is directly proportional to the amount of extra base displacement beyond the bearing design displacement $\Delta$. 
NF ground motions are rich in long period frequencies. This can lead to resonance conditions with seismically isolated structures of long fundamental periods causing undesirable higher bearing displacements. Such resonance seems obvious in this study under the first two earthquakes, particularly, using RNC- 1 and RNC-2 isolators. Although the Kocaeli and Imperial Valley earthquakes have the lowest PGA in Table 1, the resulting bearing displacements are the highest, even are higher than those produced by the San Fernando earthquake, which has the highest PGA among the used earthquakes. This is mainly attributed to the close structural and loading, dominant, frequencies.

Based on the above results, adding more hysteretic damping to the RNC isolator improves the behavior of the isolated structures in terms of reducing the bearing displacements and the resulting pounding intensity, if there is any. But, practically, this solution should not obstruct the isolator itself to achieve efficient isolation regarding reducing the peak absolute structural accelerations. To investigate that, the corresponding peak absolute structural accelerations of the case study shown in Fig. 13 are obtained and listed

Table 2

Peak absolute structural accelerations using different RNC isolators with and without buffer mechanisms $\left(\mathrm{m} / \mathrm{s}^{2}\right)$.

\begin{tabular}{|c|c|c|c|c|c|c|c|c|c|c|c|c|c|c|c|c|c|}
\hline \multirow{2}{*}{$\begin{array}{l}\text { Earthquake } \\
\text { number }\end{array}$} & \multirow{2}{*}{$\begin{array}{l}\text { Fixed } \\
\text { base }\end{array}$} & \multicolumn{4}{|l|}{ RNC-1 } & \multicolumn{4}{|l|}{ RNC-2 } & \multicolumn{4}{|l|}{ RNC-3 } & \multicolumn{4}{|l|}{ RNC-4 } \\
\hline & & $\begin{array}{l}\text { No } \\
\text { buffer }\end{array}$ & $(\%)$ & $\begin{array}{l}\text { With } \\
\text { buffer }\end{array}$ & $(\%)$ & $\begin{array}{l}\text { No } \\
\text { buffer }\end{array}$ & $(\%)$ & $\begin{array}{l}\text { With } \\
\text { buffer }\end{array}$ & $(\%)$ & $\begin{array}{l}\text { No } \\
\text { buffer }\end{array}$ & $(\%)$ & $\begin{array}{l}\text { With } \\
\text { buffer }\end{array}$ & $(\%)$ & $\begin{array}{l}\text { No } \\
\text { buffer }\end{array}$ & $(\%)$ & $\begin{array}{l}\text { With } \\
\text { buffer }\end{array}$ & $(\%)$ \\
\hline \multicolumn{18}{|c|}{$25 \%$ lighter structure } \\
\hline 1 & 7.35 & 0.890 & 88 & 15.883 & -116 & 1.095 & 85 & 1.095 & 85 & 1.487 & 80 & 1.487 & 80 & 1.946 & 74 & 1.946 & 74 \\
\hline 2 & 9.50 & 1.129 & 88 & 22.698 & -139 & 1.534 & 84 & 11.442 & -20 & 1.790 & 81 & 1.790 & 81 & 2.351 & 75 & 2.351 & 75 \\
\hline 3 & 19.91 & 1.028 & 95 & 1.028 & 95 & 1.684 & 92 & 1.684 & 92 & 1.912 & 90 & 1.912 & 90 & 2.334 & 88 & 2.334 & 88 \\
\hline 4 & 28.77 & 0.711 & 98 & 5.028 & 83 & 1.282 & 96 & 1.282 & 96 & 1.590 & 94 & 1.590 & 94 & 2.078 & 93 & 2.078 & 93 \\
\hline 5 & 53.01 & 1.092 & 98 & 1.092 & 98 & 1.693 & 97 & 1.693 & 97 & 1.808 & 97 & 1.808 & 97 & 2.246 & 96 & 2.246 & 96 \\
\hline \multicolumn{18}{|c|}{ Normal weight structure } \\
\hline 1 & 11.35 & 0.616 & 95 & 14.538 & -28 & 0.988 & 91 & 4.209 & 63 & 1.176 & 90 & 1.176 & 90 & 1.508 & 87 & 1.508 & 87 \\
\hline 2 & 15.15 & 0.924 & 94 & 22.809 & -51 & 1.329 & 91 & 16.814 & -11 & 1.495 & 90 & 8.783 & 42 & 1.745 & 88 & 1.745 & 88 \\
\hline 3 & 24.66 & 1.064 & 96 & 1.064 & 96 & 1.498 & 94 & 1.498 & 94 & 1.521 & 94 & 1.521 & 94 & 1.741 & 93 & 1.741 & 93 \\
\hline 4 & 21.55 & 0.654 & 97 & 9.104 & 58 & 0.996 & 95 & 0.996 & 95 & 1.285 & 94 & 1.285 & 94 & 1.664 & 92 & 1.664 & 92 \\
\hline 5 & 44.26 & 0.728 & 98 & 0.728 & 98 & 1.265 & 97 & 1.265 & 97 & 1.530 & 97 & 1.530 & 97 & 2.000 & 95 & 2.000 & 95 \\
\hline \multicolumn{18}{|c|}{$25 \%$ heavier structure } \\
\hline 1 & 10.51 & 0.486 & 95 & 14.652 & -39 & 0.847 & 92 & 10.994 & -5 & 1.057 & 90 & 3.067 & 71 & 1.287 & 88 & 1.287 & 88 \\
\hline 2 & 13.32 & 0.746 & 94 & 22.773 & -71 & 1.206 & 91 & 19.280 & -45 & 1.355 & 90 & 12.683 & 5 & 1.525 & 89 & 7.324 & 45 \\
\hline 3 & 27.89 & 0.696 & 98 & 0.696 & 98 & 1.207 & 96 & 1.207 & 96 & 1.288 & 95 & 1.288 & 95 & 1.525 & 95 & 1.525 & 95 \\
\hline 4 & 19.56 & 0.566 & 97 & 10.414 & 47 & 0.958 & 95 & 1.769 & 91 & 1.104 & 94 & 1.104 & 94 & 1.375 & 93 & 1.375 & 93 \\
\hline 5 & 34.22 & 0.680 & 98 & 0.680 & 98 & 1.154 & 97 & 3.445 & 90 & 1.230 & 96 & 1.230 & 96 & 1.639 & 95 & 1.639 & 95 \\
\hline
\end{tabular}
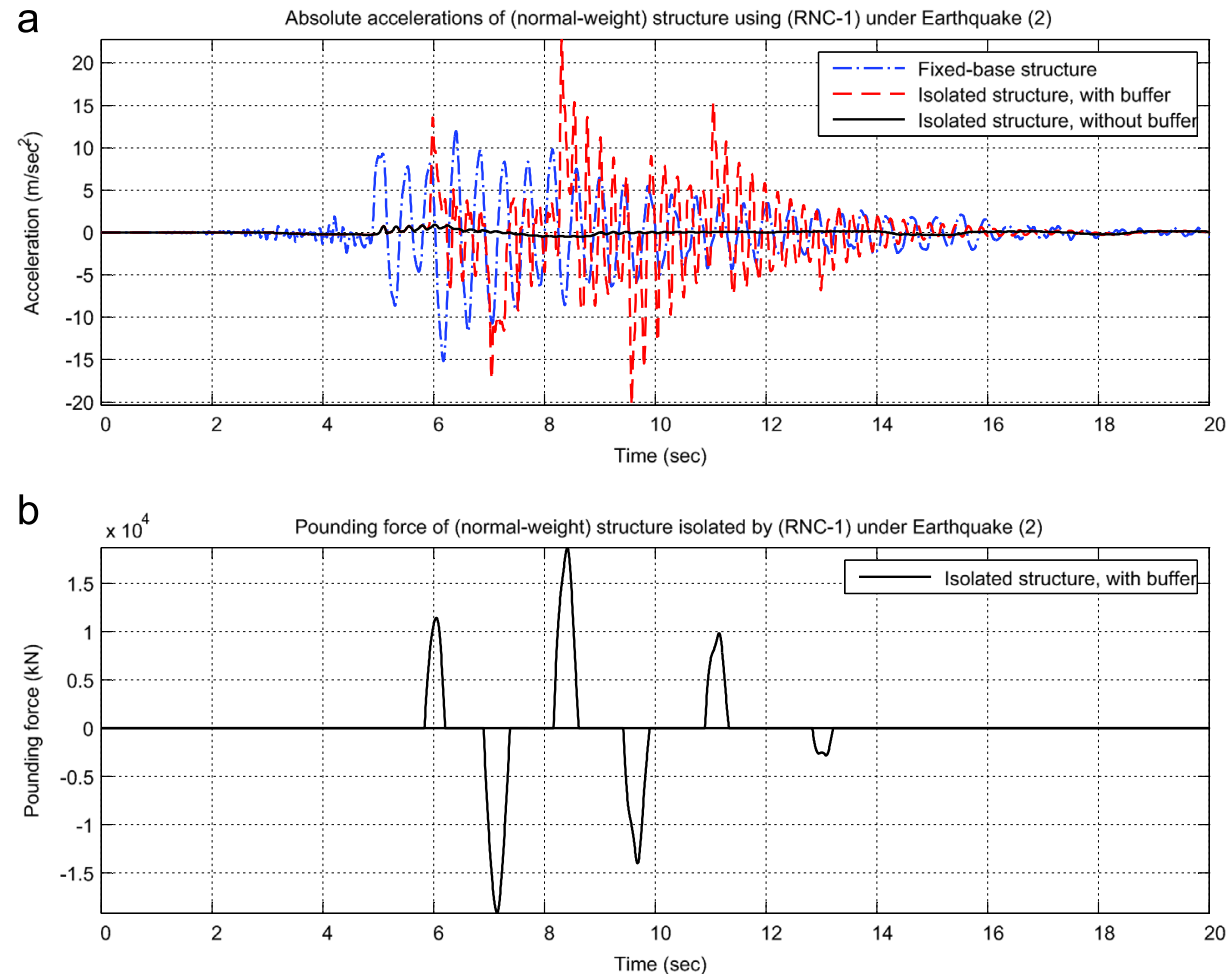

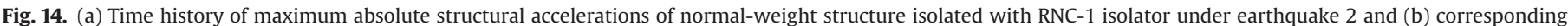
pounding force in the case of isolation with buffer. 
in Table 2. The performance measure is taken as the reduction percentage of acceleration responses. This percentage (\%) is expressed as

$\left.\%=\frac{\left(\ddot{x}_{\text {fixed }- \text { base }}\right)-\left(\ddot{x}_{\text {RNC-isolated }}\right)}{\left(\ddot{x}_{\text {fixed }} \text {-base }\right.}\right) \times 100$

where $\ddot{x}_{\text {fixed-base }}$ is the peak acceleration of fixed-base structure and $\ddot{x}_{\text {RNC-isolated }}$ is the peak acceleration of RNC-isolated structure. The negative values of $\%$ in Table 2 indicate the undesired negative effect of pounding on structural accelerations. From this table, the following conclusions could be drawn:

1. Increasing the isolator hysteretic damping slightly reduces the peak accelerations of the isolated structure.

2. Intense pounding of an isolated structure results in structural accelerations higher than those of its fixed base case. This becomes more obvious in structures with relatively light weight.

3. Increasing the isolator hysteretic damping can remarkably attenuate the undesirable increase of the structural accelerations due to pounding.

4. The RNC isolator can achieve high levels of structural accelerations reduction, especially under severe ground motions.

5. Where there is no pounding, isolation of light-weight structures is less efficient under low-intensity earthquakes compared to heavier structures under the same earthquakes. This isolation efficiency becomes higher under more severe earthquakes showing similar behavior to that of heavier structures under such strong earthquakes.

To make the above items 2-4 more clear, a sample of the absolute structural acceleration time history response is shown in
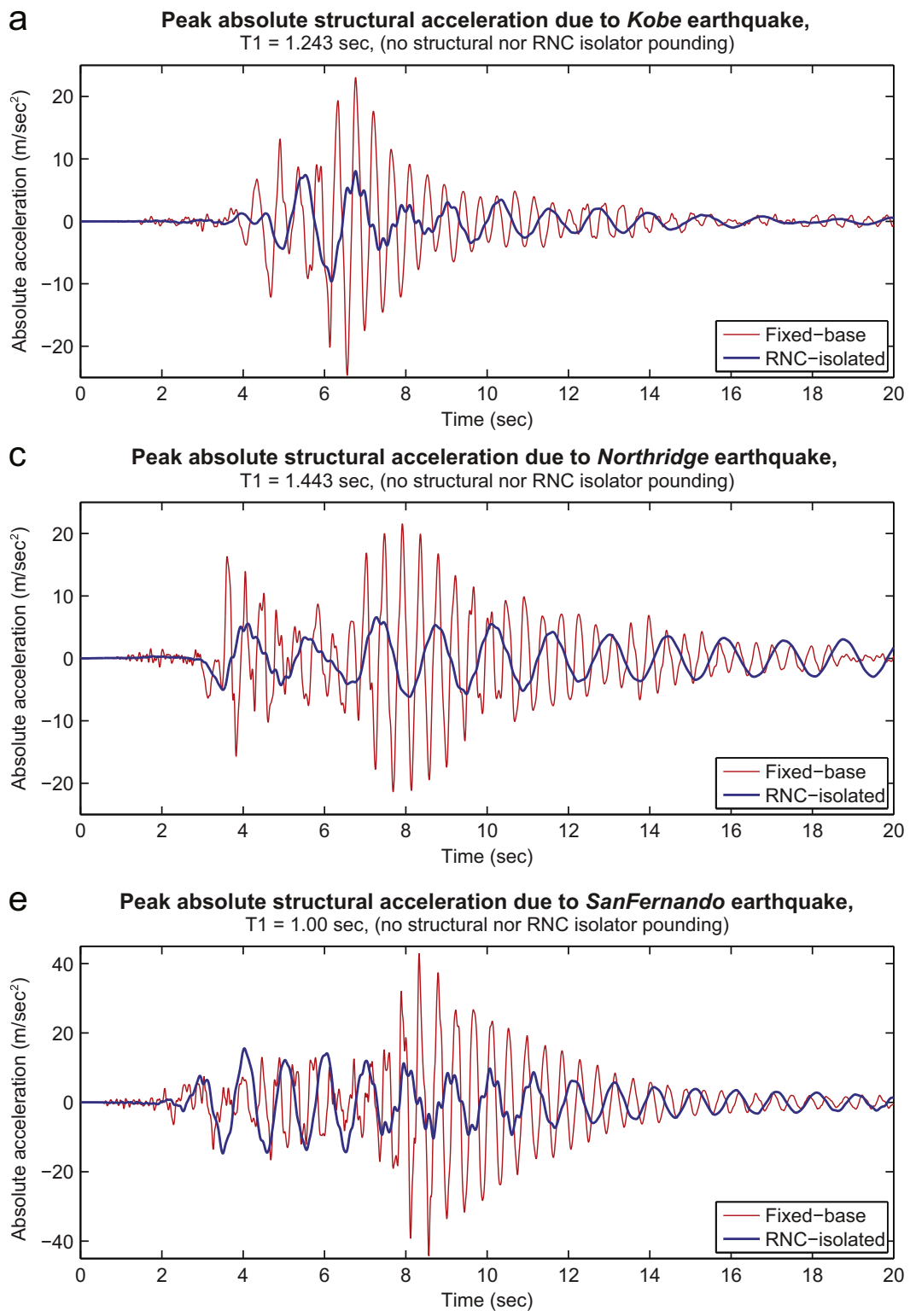

b Peak response quantities $R N C$ Xdes $=30 \mathrm{~cm}$, Seismic gap $=38 \mathrm{~cm}$

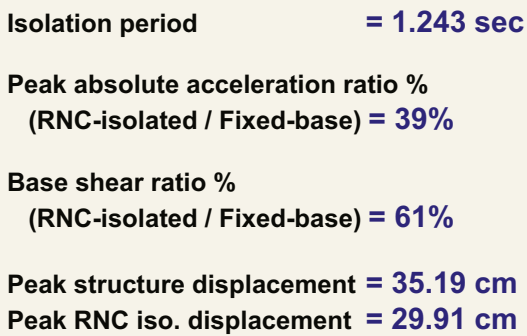

d Peak response quantities $R N C$ Xdes $=30 \mathrm{~cm}$, Seismic gap $=38 \mathrm{~cm}$

\begin{tabular}{|l|} 
Isolation period $=1.443 \mathrm{sec}$ \\
Peak absolute acceleration ratio $\%$ \\
(RNC-isolated $/$ Fixed-base) $=31 \%$ \\
Base shear ratio \% \\
(RNC-isolated $/$ Fixed-base) $=50 \%$ \\
Peak structure displacement $=32.95 \mathrm{~cm}$ \\
Peak RNC iso. displacement $=29.39 \mathrm{~cm}$
\end{tabular}

Peak response quantities $R N C$ Xdes $=30 \mathrm{~cm}$, Seismic gap $=38 \mathrm{~cm}$

\begin{tabular}{|c|c|}
\hline Isolation period & $=1.000 \mathrm{sec}$ \\
\hline $\begin{array}{l}\text { Peak absolute a } \\
\text { (RNC-isolated }\end{array}$ & $\begin{array}{l}\text { atio } \% \\
=35 \%\end{array}$ \\
\hline $\begin{array}{l}\text { Base shear ratio } \\
\text { (RNC-isolated }\end{array}$ & $=64 \%$ \\
\hline $\begin{array}{l}\text { Peak structure } \\
\text { Peak RNC iso. } \mathrm{d}\end{array}$ & $\begin{aligned} \mathrm{t} & =37.56 \mathrm{~cm} \\
& =29.06 \mathrm{~cm}\end{aligned}$ \\
\hline
\end{tabular}

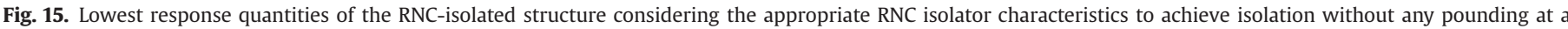

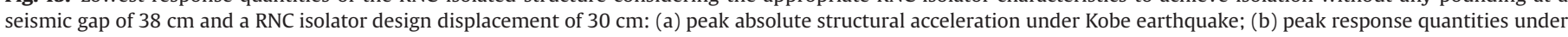

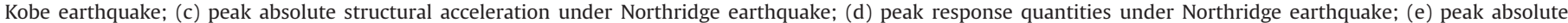
structural acceleration under San Fernando earthquake; (f) peak response quantities under San Fernando earthquake. 


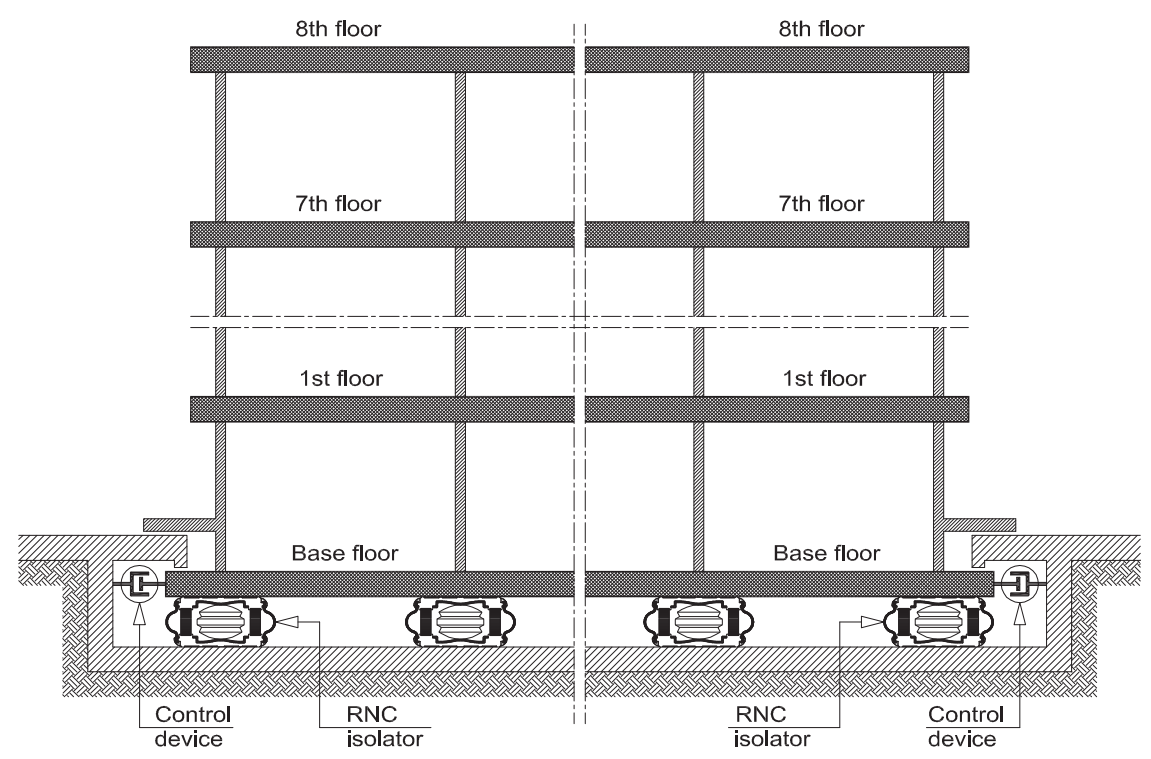

Fig. 16. Idealized RNC-isolated structural model with control devices.

Fig. 14(a) for the normal weight structure and RNC-1 isolator under earthquake 2, considering three cases: (1) fixed-base structure; (2) isolated structure with buffer mechanism; and (3) isolated structure without buffer mechanism. The corresponding pounding force in case 2, considering the buffer mechanism, is plotted in Fig. 14(b). Fig. 14(a) shows that the absence of buffer mechanism leads to significant reduction of structural accelerations contrary to the case of considering the buffer mechanism, where the structural accelerations are not only amplified but also the structure suffers high pounding force as demonstrated in Fig. 14(b). This represents the undesirable effects of buffer mechanism. However, if the RNCisolated structure is designed to endure the exceptional high accelerations due to pounding, this will preserve structural safety, prevent occupants' injury and properties' damage under severe earthquakes stronger than the design earthquake. Certainly, this obtained benefit after incorporating the buffer mechanism is priceless under such catastrophic earthquakes. Another advantage which makes the inner pounding preferable to the potential pounding with the surrounding moat wall or an adjacent structure is that the RNC isolator distributes any possible pounding regularly on the in-plan floor area of the isolated floor mass. This prevents local concentration of the overall pounding at one or more points or over a certain edge length in the case of using surrounding moat walls. Moreover, the rebound velocities of the superstructure after pounding are expected to be lower using the RNC isolators because of the large number of their metallic yield dampers, contrary to the case of pounding with rigid moat walls.

Fig. 14 shows the negative effect of buffer activation on structural accelerations. Such negative effect could be minimized using a RNC isolator with optimized characteristics for each excitation. Such optimization of isolator characteristics is carried out in this paper by trial and error method for the Kobe, Northridge and San Fernando earthquakes. The three optimization criteria are: (1) entire avoidance of direct seismic pounding of RNC-isolated superstructure with adjacent structures; (2) entire avoidance of pounding of the RNC isolator; and (3) achieving the maximum structural response reductions under limited seismic gaps. Fig. 15 demonstrates the resulting reductions in peak structural responses using the most adequate design of the RNC isolator under each of the three NF ground motions. The main outcome of this figure is that the RNC isolator is able to reduce the peak structural response quantities to a reasonably accepted degree at very small isolation periods under severe NF earthquakes and limited seismic gaps with absolutely no structure-to-structure pounding nor RNC inner pounding. Such small isolation periods of the RNC isolator, which have achieved response reductions up to $69 \%$, represent around one-half or onethird the required isolation periods of other seismic isolation systems to initiate efficient isolation.

\section{Hybrid RNC isolator}

Under severe seismic excitations, the suspended base of the RNC-isolated structure may arrive at the end of the isolator design displacement $\Delta$ when the structure still has considerable kinetic energy, due to high base velocity, causing severe pounding. In this section, the RNC isolator is allowed to behave as a purely passive isolation system, with hysteretic damping, within a specific (prescribed) range below the design bearing displacement $\Delta$ as denoted in Fig. 2 by $\Delta_{\text {p }}$ or stage 1 . Then active control force is applied to the isolated base from the end of stage 1 up to the end of stage 2 as denoted by $\Delta_{\mathrm{h}}$, after which pounding will take place. The resulting hybrid isolation system, shown in Fig. 16, aims to reduce the bearing displacement and represents an alternative or even a supplementary approach to that presented in Section 5. Let $u$ and $x_{\mathrm{b}}$ denote the active control force and the horizontal isolated base displacement, respectively. In mathematical form, this strategy may be expressed as

if $\left|x_{\mathrm{b}}\right|<\Delta_{\mathrm{p}}, \quad u$ is deactivated (passive mode)

else $\left|x_{\mathrm{b}}\right| \geq \Delta_{\mathrm{p}}, \quad u$ is activated (hybrid mode)

\subsection{Modeling of hybrid RNC-isolated structure}

The equations of motion of an $\mathrm{N}$-story linear shear type superstructure subjected to earthquake excitation is written in the matrix form as

$\mathbf{M}_{\mathrm{s}} \ddot{\mathbf{x}}_{\mathrm{s}}+\mathbf{C}_{\mathrm{s}} \dot{\mathbf{x}}_{\mathrm{s}}+\mathbf{K}_{\mathrm{s}} \mathbf{x}_{\mathrm{s}}=-\mathbf{M}_{\mathrm{s}}\{\mathbf{1}\}\left(\ddot{x}_{\mathrm{b}}+\ddot{x}_{\mathrm{g}}\right)$

where $\mathbf{M}_{s}, \mathbf{K}_{s}$, and $\mathbf{C}_{s}$ are the $N \times N$ mass, stiffness and damping matrices of the superstructure, respectively; $\mathbf{x}_{\mathrm{s}}=\left\{x_{1}, x_{2}, \ldots, x_{N}\right\}^{T}$ is the relative displacement vector of the superstructure; $\dot{\mathbf{x}}_{\mathrm{S}}$ and $\ddot{\mathbf{x}}_{\mathrm{S}}$ are the relative velocity and acceleration vectors, respectively; $x_{j}(j=1,2, \ldots, N)$ is the lateral displacement of the $j$ th floor relative to the base mass; $\{\mathbf{1}\}=\{1,1,1, \ldots, 1\}^{T}$ is the influence coefficient 
a

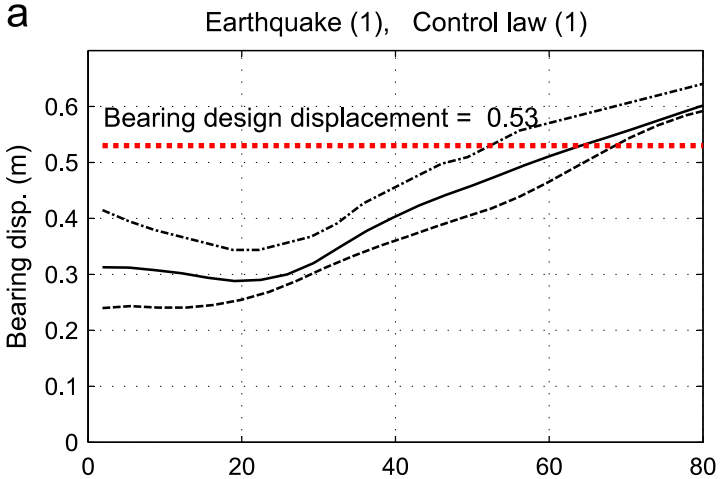

C

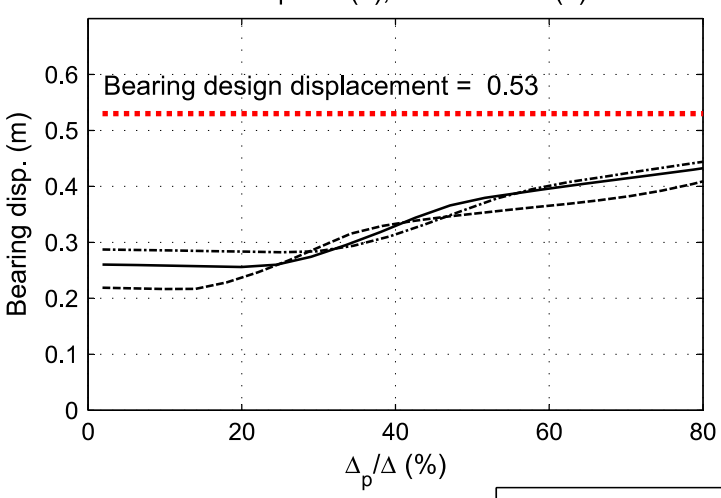

b

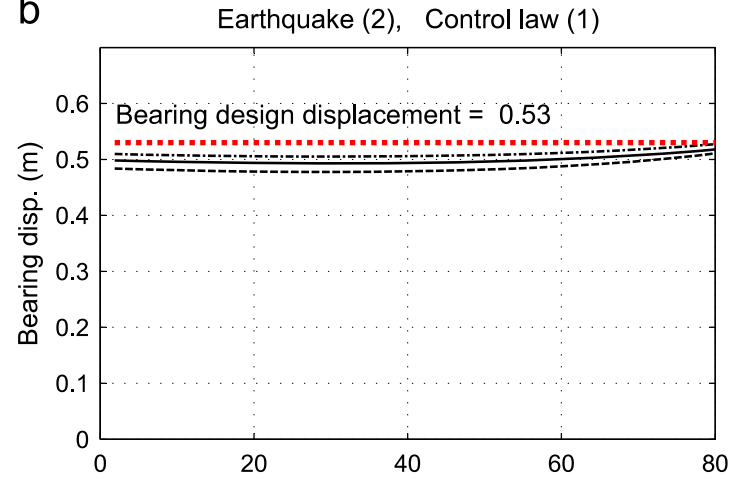

d Earthquake (5), Control law (1)

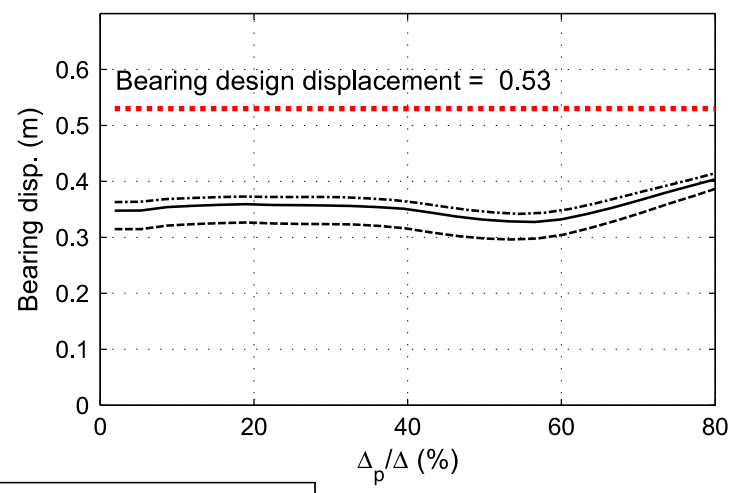

Normal-weigt structure, control law 1

------25\% light-weigt structure, control law 1

-...... 25\% heavy-weigt structure, control law 1

Fig. 17. Peak actively controlled bearing displacements using control law 1 under: (a) earthquakes 1 ; (b) earthquake 2 ; (c) earthquake 4 ; and (d) earthquake 5.

vector; $\ddot{x}_{\mathrm{b}}$ is the relative acceleration of the base mass; and $\ddot{x}_{\mathrm{g}}$ is the earthquake ground acceleration.

The equation of motion of the base mass is given by

$m_{\mathrm{b}} \ddot{x}_{\mathrm{b}}+\eta F_{\mathrm{b}}-c_{1} \dot{x}_{1}-k_{1} x_{1}=-m_{\mathrm{b}} \ddot{x}_{\mathrm{g}}+u$

where $m_{\mathrm{b}}$ is the suspended mass of the base raft; $c_{1}$ and $k_{1}$ are the damping and stiffness of the first story, respectively; $\eta$ is the total number of RNC isolators; $F_{\mathrm{b}}$ is the restoring force transmitted to the suspended base mass by a single RNC isolator and $u$ is the active control force. The RNC isolator restoring force $F_{\mathrm{b}}$ is represented by Eq. (14) as explained in Section 3.

\subsection{Controler design}

Two active control laws are considered in this study. The first is a simple static discontinuous active bang-bang type control, which was developed using only the measurement of velocity of the suspended base floor of an isolated structure as a feedback information [27]. The control force is expressed as

$u=-\rho \operatorname{sign}\left(\dot{x}_{\mathrm{b}}\right)$

where $\rho$ is a design parameter and $\dot{x}_{\mathrm{b}}$ is the velocity of the suspended base floor of the isolated structure.

The second controller is based on using a passive static hyperbolic function depending only on the base floor velocity [39]. This function ensures energy dissipation capability with always bounded control force. The control law is

$u=-\rho \operatorname{sech}\left(\frac{\dot{x}_{\mathrm{b}}}{a}\right) \tanh \left(\frac{\dot{x}_{\mathrm{b}}}{a}\right)$

where $\rho>0$ and $a>0$ are design parameters.

\subsection{Parametric study}

Using the RNC isolator, the probable pounding (if any) will take place within the isolator components when the displacement of the suspended base floor reaches the end of the bearing design displacement $\Delta$ with considerable amount of kinetic energy. The undesirable pounding effects are then reflected first on the suspended base floor, as the first structural part connected to the RNC isolator, then spread through the isolated structure. Combining active control force to the passive RNC isolator is studied in this section as a possible alternative or supplementary means of reducing the isolated base floor displacement to alleviate or even eliminate pounding. The efficiency of both control laws given by Eqs. (20) and (21) was examined in terms of bearing displacement. Then, the influence of the resulting overall hybrid isolation system, shown in Fig. 16, on the isolation efficiency is investigated in terms of peak structural absolute acceleration.

The three isolated structures of Section 5 are studied along with only the RNC-1 isolator under earthquakes 1, 2, 4 and 5. Active control force is applied to the base over the whole range of the bearing design displacement $\Delta$, such that $\Delta_{\mathrm{p}}=[1 \mathrm{~cm}-\Delta \mathrm{cm}]$ with an increment of $1 \mathrm{~cm}$. This to investigate the variation of the peak bearing displacement against the ratio $\Delta_{\mathrm{p}} / \Delta$, which represents the percentage of design displacement $\Delta$ over which the RNC isolator is 
a

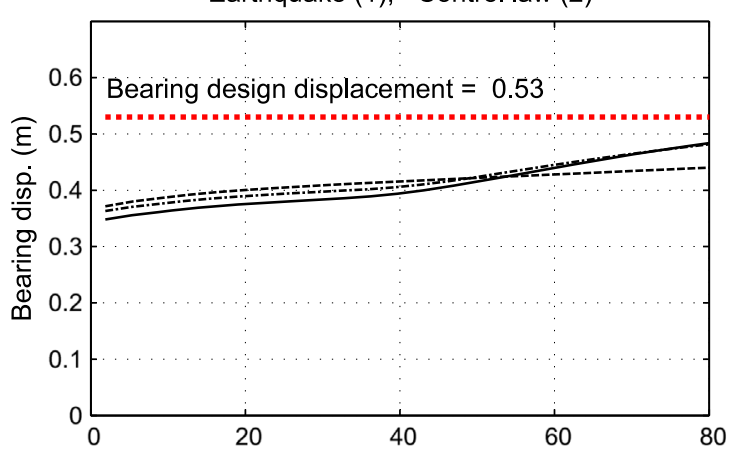

C

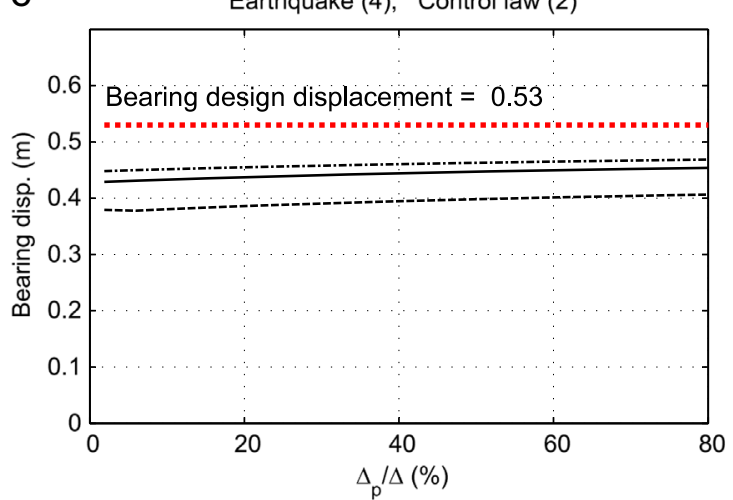

b

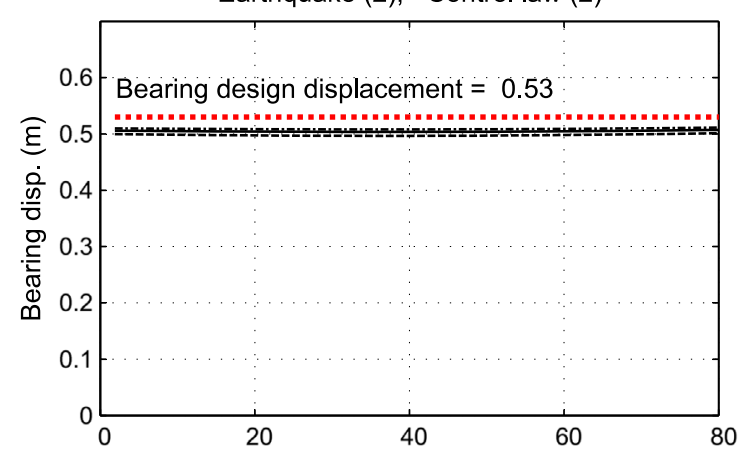

d

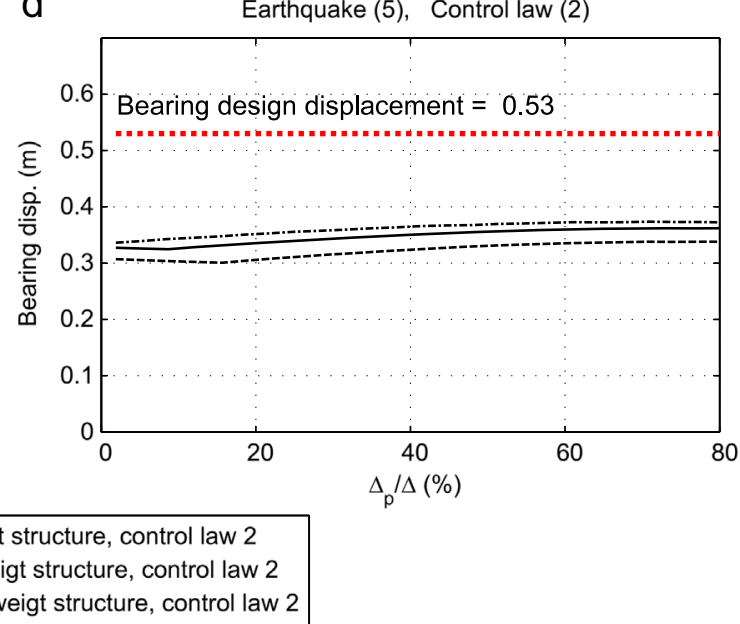

Fig. 18. Peak actively controlled bearing displacements using control law 2 under: (a) earthquakes 1 ; (b) earthquake 2 ; (c) earthquake 4 ; and (d) earthquake 5.

purely passive, while it becomes hybrid isolation system over the remaining percentage of $\Delta$. Fig. 17 shows the variation of the resulting peak bearing displacements against the ratio $\Delta_{\mathrm{p}} / \Delta$ under four earthquakes considering the first control law given by Eq. (20). The second control law, given by Eq. (21), is considered in Fig. 18.

In Fig. 17, although the structural behavior is different under the four earthquakes, there is a similar general trend of all curves. The integration of active control with the passive RNC isolator at smaller $\Delta_{\mathrm{p}} / \Delta$ ratios leads to a more effective hybrid RNC isolator in reducing the bearing displacement than at larger $\Delta_{\mathrm{p}} / \Delta$ ratios. This means that the larger the $\Delta_{\mathrm{h}}$ over which the RNC isolator is hybrid, the wider the range over which the bearing displacement can change its direction before coming to the end of design displacement limit $\Delta$. The hybrid RNC isolator is also able to reduce bearing displacements at higher $\Delta_{\mathrm{p}} / \Delta$ ratios, but in this case the remaining displacement range is not enough for changing the direction of motion before reaching the design displacement limit $\Delta$, which means that pounding will happen but more probably with less intensity.

The second control law is tuned to produce the same average control force produced by the first control law. Then it is used to reproduce the above study of Fig. 17, and the results are represented in Fig. 18 using a control force of nearly three times that of the first control law. Fig. 18(a) shows a similar general trend to that demonstrated in Fig. 17. The other response curves of Fig. 18(b)-(d) are more flat and prove the ability of the hybrid RNC isolator to obtain bearing displacements lower than the design limit $\Delta$ to avoid pounding but on the account of much higher control forces.

To examine how practical is the hybrid RNC isolator, its influence on the isolation efficiency is investigated under earthquakes 1 and 2 considering the peak absolute structural acceleration as a performance measure. The three structures of different masses are included in this study. For each structure, the range of active control forces, using the first control law in Eq. (20), is applied to the isolated base at three different values of the ratio $\Delta_{\mathrm{p}} / \Delta$. These values are $20 \%, 50 \%$ and $80 \%$. They are chosen to represent the early, fair and late integration of the active control forces to the passive RNC isolator to form a hybrid isolation system, respectively. The bearing displacement, pounding force (if any) and the peak absolute acceleration corresponding to every control force are obtained and listed in Table 3 under earthquake 1 and Table 4 under earthquake 2. The obtained acceleration responses, considering the buffer mechanism, are compared to those of the cases of RNC-isolated structures without buffer and fixed-base structures. The extensive study listed in Tables 3 and 4 leads to the following conclusions:

1. The early incorporation of active control forces to the RNC isolator leads to the best results in terms of avoiding pounding and obtaining structural accelerations lower than those of the fixed-base case using low control forces. On the other hand, the later incorporation of such active control forces cannot lead to satisfactory results even by using much higher values active control forces.

2. Increasing the control force leads to less efficient seismic isolation as the peak structural acceleration in this case exceeds that of the fixed-base case. This is mainly attributed to the more added rigidity to the isolation system, which certainly decreases the degree of structure-ground decoupling. Such increasing isolator rigidity enables more seismic forces to be transmitted into the isolated structure.

3. Pounding intensity (if any) greatly increases as the structural mass increases. 
Table 3

Peak structural responses against control force under earthquake 1 (ton-m-s).

\begin{tabular}{|c|c|c|c|c|c|c|c|c|c|c|c|c|c|c|c|c|c|}
\hline \multicolumn{6}{|c|}{$25 \%$ lighter structure } & \multicolumn{6}{|c|}{ Normal weight structure } & \multicolumn{6}{|c|}{$25 \%$ heavier structure } \\
\hline \multirow[t]{2}{*}{$\begin{array}{l}\text { Control } \\
\text { force }\end{array}$} & \multirow[t]{2}{*}{$\begin{array}{l}\text { Pounding } \\
\text { force }\end{array}$} & \multirow[t]{2}{*}{$\begin{array}{l}\text { Base } \\
\text { disp. }\end{array}$} & \multicolumn{2}{|c|}{$\begin{array}{l}\text { Acceleration } \\
\text { (isolated) }\end{array}$} & \multirow[t]{2}{*}{$\begin{array}{l}\text { Accel. } \\
\text { (fixed b.) }\end{array}$} & \multirow[t]{2}{*}{$\begin{array}{l}\text { Control } \\
\text { force }\end{array}$} & \multirow[t]{2}{*}{$\begin{array}{l}\text { Pounding } \\
\text { force }\end{array}$} & \multirow[t]{2}{*}{$\begin{array}{l}\text { Base } \\
\text { disp. }\end{array}$} & \multicolumn{2}{|c|}{$\begin{array}{l}\text { Acceleration } \\
\text { (isolated) }\end{array}$} & \multirow[t]{2}{*}{$\begin{array}{l}\text { Accel. } \\
\text { (fixed b.) }\end{array}$} & \multirow[t]{2}{*}{$\begin{array}{l}\text { Control } \\
\text { force }\end{array}$} & \multirow[t]{2}{*}{$\begin{array}{l}\text { Pounding } \\
\text { force }\end{array}$} & \multirow[t]{2}{*}{$\begin{array}{l}\text { Base } \\
\text { disp. }\end{array}$} & \multicolumn{2}{|c|}{$\begin{array}{l}\text { Acceleration } \\
\text { (isolated) }\end{array}$} & \multirow[t]{2}{*}{$\begin{array}{l}\text { Accel. } \\
\text { (fixed b.) }\end{array}$} \\
\hline & & & Buffer & $\begin{array}{l}\text { No } \\
\text { buffer }\end{array}$ & & & & & Buffer & $\begin{array}{l}\text { No } \\
\text { buffer }\end{array}$ & & & & & Buffer & $\begin{array}{l}\text { No } \\
\text { buffer }\end{array}$ & \\
\hline \multicolumn{18}{|c|}{$\Delta_{\mathrm{p}} / \Delta=20 \%$, Earthquake 1} \\
\hline 220.9 & 177.5 & 0.548 & 5.86 & 0.89 & 7.35 & 248.7 & 735.0 & 0.604 & 10.54 & 0.62 & 11.35 & 266.1 & 1083.0 & 0.638 & 11.89 & 0.49 & 10.51 \\
\hline 342.7 & 0.0 & 0.449 & 3.45 & 0.89 & 7.35 & 449.0 & 249.6 & 0.555 & 8.80 & 0.62 & 11.35 & 486.5 & 625.2 & 0.593 & 9.99 & 0.49 & 10.51 \\
\hline 396.4 & 0.0 & 0.238 & 4.36 & 0.89 & 7.35 & 552.2 & 0.0 & 0.290 & 4.90 & 0.62 & 11.35 & 770.6 & $\mathbf{0 . 0}$ & 0.491 & 4.79 & 0.49 & 10.51 \\
\hline 412.6 & 0.0 & 0.312 & 4.27 & 0.89 & 7.35 & 598.5 & 0.0 & 0.256 & 5.38 & 0.62 & 11.35 & 779.1 & 0.0 & 0.366 & 4.58 & 0.49 & 10.51 \\
\hline 459.9 & 0.0 & 0.221 & 4.86 & 0.89 & 7.35 & 601.7 & 0.0 & 0.407 & 4.58 & 0.62 & 11.35 & 774.4 & 0.0 & 0.230 & 5.20 & 0.49 & 10.51 \\
\hline 526.9 & 0.0 & 0.211 & 5.25 & 0.89 & 7.35 & 671.3 & 0.0 & 0.240 & 5.67 & 0.62 & 11.35 & 812.4 & 0.0 & 0.269 & 5.42 & 0.49 & 10.51 \\
\hline 583.6 & 0.0 & 0.203 & 6.17 & 0.89 & 7.35 & 730.5 & 0.0 & 0.228 & 6.19 & 0.62 & 11.35 & 857.7 & 0.0 & 0.249 & 5.94 & 0.49 & 10.51 \\
\hline 630.5 & 0.0 & 0.196 & 7.30 & 0.89 & 7.35 & 777.3 & 0.0 & 0.217 & 6.46 & 0.62 & 11.35 & 909.7 & 0.0 & 0.236 & 6.50 & 0.49 & 10.51 \\
\hline 669.2 & 0.0 & 0.190 & 8.43 & 0.89 & 7.35 & 814.3 & 0.0 & 0.208 & 6.86 & 0.62 & 11.35 & 950.3 & 0.0 & 0.225 & 7.03 & 0.49 & 10.51 \\
\hline 701.9 & 0.0 & 0.184 & 9.43 & 0.89 & 7.35 & 843.5 & 0.0 & 0.200 & 9.08 & 0.62 & 11.35 & 981.8 & 0.0 & 0.215 & 7.33 & 0.49 & 10.51 \\
\hline 729.4 & 0.0 & 0.179 & 10.33 & 0.89 & 7.35 & 867.3 & 0.0 & 0.193 & 9.69 & 0.62 & 11.35 & 1006.0 & 0.0 & 0.207 & 7.49 & 0.49 & 10.51 \\
\hline \multicolumn{18}{|c|}{$\Delta_{\mathrm{p}} / \Delta=50 \%$, Earthquake 1} \\
\hline 160.8 & 566.3 & 0.587 & 10.91 & 0.89 & 7.35 & 185.4 & 1058.0 & 0.636 & 14.14 & 0.62 & 11.35 & 206.4 & 1478.0 & 0.678 & 16.96 & 0.49 & 10.51 \\
\hline 287.3 & 223.0 & 0.552 & 8.70 & 0.89 & 7.35 & 325.2 & 602.0 & 0.59 & 10.74 & 0.62 & 11.35 & 367.3 & 1023.0 & 0.632 & 14.94 & 0.49 & 10.51 \\
\hline 424.4 & 0.0 & 0.477 & 5.09 & 0.89 & 7.35 & 543.4 & 67.0 & 0.537 & 5.59 & 0.62 & 11.35 & 629.2 & 496.0 & 0.580 & 9.34 & 0.49 & 10.51 \\
\hline 551.2 & 0.0 & 0.449 & 6.42 & 0.89 & 7.35 & 648.4 & 0.0 & 0.481 & 5.75 & 0.62 & 11.35 & 845.8 & 169.3 & 0.547 & 9.17 & 0.49 & 10.51 \\
\hline 635.9 & 0.0 & 0.424 & 8.04 & 0.89 & 7.35 & 794.5 & 0.0 & 0.464 & 6.30 & 0.62 & 11.35 & 1067.0 & 16.9 & 0.532 & 8.35 & 0.49 & 10.51 \\
\hline 710.1 & 0.0 & 0.407 & 8.96 & 0.89 & 7.35 & 912.0 & 0.0 & 0.447 & 7.87 & 0.62 & 11.35 & 1219.0 & 0.0 & 0.509 & 9.55 & 0.49 & 10.51 \\
\hline 774.4 & 0.0 & 0.391 & 9.70 & 0.89 & 7.35 & 1010.0 & 0.0 & 0.433 & 9.14 & 0.62 & 11.35 & 1349.0 & 0.0 & 0.490 & 10.69 & 0.49 & 10.51 \\
\hline 827.4 & 0.0 & 0.383 & 10.30 & 0.89 & 7.35 & 1090.0 & 0.0 & 0.421 & 11.19 & 0.62 & 11.35 & 1463.0 & 0.0 & 0.474 & 11.30 & 0.49 & 10.51 \\
\hline 870.5 & 0.0 & 0.374 & 10.95 & 0.89 & 7.35 & 1154.0 & 0.0 & 0.409 & 13.26 & 0.62 & 11.35 & 1562.0 & 0.0 & 0.460 & 11.42 & 0.49 & 10.51 \\
\hline 906.0 & 0.0 & 0.366 & 11.83 & 0.89 & 7.35 & 1205.0 & 0.0 & 0.399 & 14.92 & 0.62 & 11.35 & 1641.0 & 0.0 & 0.447 & 11.26 & 0.49 & 10.51 \\
\hline 935.7 & 0.0 & 0.359 & 13.14 & 0.89 & 7.35 & 1247.0 & 0.0 & 0.390 & 16.29 & 0.62 & 11.35 & 1698.0 & 0.0 & 0.435 & 11.01 & 0.49 & 10.51 \\
\hline \multicolumn{18}{|c|}{$\Delta_{\mathrm{p}} / \Delta=80 \%$, Earthquake 1} \\
\hline 94.3 & 826.2 & 0.613 & 14.57 & 0.89 & 7.35 & 116.6 & 1273.0 & 0.657 & 14.34 & 0.62 & 11.35 & 127.5 & 1491.0 & 0.679 & 16.85 & 0.49 & 10.51 \\
\hline 175.2 & 692.1 & 0.599 & 12.72 & 0.89 & 7.35 & 218.1 & 1121.0 & 0.642 & 14.08 & 0.62 & 11.35 & 272.1 & 1661.0 & 0.696 & 16.76 & 0.49 & 10.51 \\
\hline 315.2 & 515.9 & 0.582 & 12.17 & 0.89 & 7.35 & 386.4 & 872.1 & 0.617 & 13.5 & 0.62 & 11.35 & 490.8 & 1394.0 & 0.669 & 16.56 & 0.49 & 10.51 \\
\hline 433.7 & 385.6 & 0.569 & 12.35 & 0.89 & 7.35 & 515.4 & 658.0 & 0.596 & 11.76 & 0.62 & 11.35 & 649.6 & 1105.0 & 0.641 & 16.48 & 0.49 & 10.51 \\
\hline 542.1 & 295.2 & 0.560 & 11.64 & 0.89 & 7.35 & 629.5 & 513.7 & 0.581 & 11.05 & 0.62 & 11.35 & 779.2 & 887.9 & 0.619 & 13.33 & 0.49 & 10.51 \\
\hline 632.3 & 204.5 & 0.551 & 10.76 & 0.89 & 7.35 & 740.9 & 421.9 & 0.572 & 9.88 & 0.62 & 11.35 & 898.6 & 737.2 & 0.604 & 12.31 & 0.49 & 10.51 \\
\hline 700.8 & 108.1 & 0.541 & 10.02 & 0.89 & 7.35 & 841.6 & 342.7 & 0.564 & 9.05 & 0.62 & 11.35 & 994.7 & 597.9 & 0.590 & 11.56 & 0.49 & 10.51 \\
\hline 747.8 & 8.3 & 0.531 & 7.64 & 0.89 & 7.35 & 929.7 & 268.2 & 0.557 & 10.18 & 0.62 & 11.35 & 1074.0 & 475.0 & 0.578 & 10.56 & 0.49 & 10.51 \\
\hline 774.4 & 0.0 & 0.521 & 8.43 & 0.89 & 7.35 & 1007.0 & 198.1 & 0.55 & 10.88 & 0.62 & 11.35 & 1144.0 & 370.2 & 0.567 & 9.73 & 0.49 & 10.51 \\
\hline 801.1 & 0.0 & 0.513 & 9.63 & 0.89 & 7.35 & 1074.0 & 133.2 & 0.543 & 11.4 & 0.62 & 11.35 & 1204.0 & 278.2 & 0.558 & 10.59 & 0.49 & 10.51 \\
\hline 827.8 & 0.0 & 0.507 & 11.00 & 0.89 & 7.35 & 1132.0 & 72.1 & 0.537 & 11.24 & 0.62 & 11.35 & 1257.0 & 197.3 & 0.550 & 12.42 & 0.49 & 10.51 \\
\hline
\end{tabular}

The values highlighted in bold, which are 0 , mean that the pounding force is 0 , so that pounding is not produced.

4. At the same control force, the bearing displacement remarkably increases with the structural mass.

5. At the same ratio of $\Delta_{\mathrm{p}} / \Delta$, heavier structures are more susceptible to intense pounding forces than lighter structures.

\section{Conclusions}

In this paper, the problem of passive and hybrid mitigation of potential inner pounding of a self-braking seismic isolation device under near-fault earthquakes has been addressed. That isolation device is a recently proposed one and is referred to as roll-n-cage (RNC) isolator. It was configured to have a built-in buffer (braking) mechanism that limits the peak isolator displacements under severe earthquakes and to prevent adjacent structural pounding. Such unique feature of the RNC isolator has been studied under nearfault destructive earthquakes, under which isolators may behave poorly as these earthquakes are rich in large long-period displacement and velocity pulses. This leads to undesired large isolators' displacements, which even destabilize the isolated structures or cause severe damage due to adjacent structural pounding. The RNC isolator was designed to avoid those problems through the integrated buffer mechanism. The main negative side effect of that mechanism is the resulting potential pounding, which has been minimized in this study via controlling the isolator's displacement using purely passive and hybrid techniques. In the passive RNC isolator mode, the effect of increasing the inherent isolator's hysteretic damping (up to a certain limit) on pounding has been investigated. In the hybrid RNC isolator mode, active control force was supplemented to the purely passive RNC isolator at a certain base displacement as a function of the measured velocity of the isolated base mass. The base velocity was chosen since it influences the kinetic energy of the isolated structure, which in turn controls the degree of severity of the potential inner RNC isolator's pounding. The hybrid RNC isolator intends to provide a non-limited mean to reduce the isolator displacements of the cases that still exhibit pounding after reaching the extent, after which the passive mode becomes limited and incapable to control base displacement. Regarding the isolation efficiency, the influence of both passive RNC isolator with increasing hysteretic damping and the hybrid isolation system on the isolation efficiency was investigated in terms of reducing the peak structural absolute acceleration. Based on the performed study, the following conclusions were drawn:

1. Increasing the isolator hysteretic damping decreases the bearing displacement and consequently alleviates the pounding intensity. 
Table 4

Peak structural responses against control force under earthquake 2 (ton-m-s)

\begin{tabular}{|c|c|c|c|c|c|c|c|c|c|c|c|c|c|c|c|c|c|}
\hline \multicolumn{6}{|c|}{$25 \%$ lighter structure } & \multicolumn{6}{|c|}{ Normal weight structure } & \multicolumn{6}{|c|}{$25 \%$ heavier structure } \\
\hline \multirow[t]{2}{*}{$\begin{array}{l}\text { Control } \\
\text { force }\end{array}$} & \multirow[t]{2}{*}{$\begin{array}{l}\text { Pounding } \\
\text { force }\end{array}$} & \multirow[t]{2}{*}{$\begin{array}{l}\text { Base } \\
\text { disp. }\end{array}$} & \multicolumn{2}{|c|}{$\begin{array}{l}\text { Acceleration } \\
\text { (isolated) }\end{array}$} & \multirow[t]{2}{*}{$\begin{array}{l}\text { Accel. } \\
\text { (fixed b.) }\end{array}$} & \multirow[t]{2}{*}{$\begin{array}{l}\text { Control } \\
\text { force }\end{array}$} & \multirow[t]{2}{*}{$\begin{array}{l}\text { Pounding } \\
\text { force }\end{array}$} & \multirow[t]{2}{*}{$\begin{array}{l}\text { Base } \\
\text { disp. }\end{array}$} & \multicolumn{2}{|c|}{$\begin{array}{l}\text { Acceleration } \\
\text { (isolated) }\end{array}$} & \multirow[t]{2}{*}{$\begin{array}{l}\text { Accel. } \\
\text { (fixed b.) }\end{array}$} & \multirow[t]{2}{*}{$\begin{array}{l}\text { Control } \\
\text { force }\end{array}$} & \multirow[t]{2}{*}{$\begin{array}{l}\text { Pounding } \\
\text { force }\end{array}$} & \multirow[t]{2}{*}{$\begin{array}{l}\text { Base } \\
\text { disp. }\end{array}$} & \multicolumn{2}{|c|}{$\begin{array}{l}\text { Acceleration } \\
\text { (isolated) }\end{array}$} & \multirow[t]{2}{*}{$\begin{array}{l}\text { Accel. } \\
\text { (fixed b.) }\end{array}$} \\
\hline & & & Buffer & $\begin{array}{l}\text { No } \\
\text { buffer }\end{array}$ & & & & & Buffer & $\begin{array}{l}\text { No } \\
\text { buffer }\end{array}$ & & & & & Buffer & $\begin{array}{l}\text { No } \\
\text { buffer }\end{array}$ & \\
\hline \multicolumn{18}{|c|}{$\Delta_{\mathrm{p}} / \Delta=20 \%$, Earthquake 2} \\
\hline 254.4 & 848.9 & 0.615 & 20.67 & 1.13 & 9.50 & 280.9 & 1377.0 & 0.668 & 22.89 & 0.92 & 15.15 & 305.4 & 1868.0 & 0.717 & 20.32 & 13.32 & 0.75 \\
\hline 451.6 & 276.5 & 0.558 & 4.09 & 1.13 & 9.50 & 503.2 & 792.2 & 0.609 & 13.46 & 0.92 & 15.15 & 561.1 & 1371.0 & 0.667 & 16.09 & 13.32 & 0.75 \\
\hline 629.5 & 0.0 & 0.421 & 6.95 & 1.13 & 9.50 & 837.2 & 0.0 & 0.525 & 7.70 & 0.92 & 15.15 & 934.2 & 431.2 & 0.573 & 11.54 & 13.32 & 0.75 \\
\hline 667.1 & 0.0 & 0.328 & 7.57 & 1.13 & 9.50 & 977.4 & 0.0 & 0.432 & 9.27 & 0.92 & 15.15 & 1209.0 & 0.0 & 0.509 & 9.32 & 13.32 & 0.75 \\
\hline 673.8 & 0.0 & 0.274 & 7.77 & 1.13 & 9.50 & 1050.0 & 0.0 & 0.368 & 9.03 & 0.92 & 15.15 & 1359.0 & 0.0 & 0.446 & 10.07 & 13.32 & 0.75 \\
\hline 708.2 & 0.0 & 0.248 & 8.91 & 1.13 & 9.50 & 1073.0 & 0.0 & 0.321 & 8.55 & 0.92 & 15.15 & 1421.0 & 0.0 & 0.390 & 9.66 & 13.32 & 0.75 \\
\hline 748.2 & 0.0 & 0.231 & 9.02 & 1.13 & 9.50 & 1086.0 & 0.0 & 0.287 & 9.65 & 0.92 & 15.15 & 1433.0 & 0.0 & 0.345 & 9.31 & 13.32 & 0.75 \\
\hline 783.0 & 0.0 & 0.218 & 8.97 & 1.13 & 9.50 & 1108.0 & 0.0 & 0.264 & 10.04 & 0.92 & 15.15 & 1454.0 & 0.0 & 0.314 & 8.91 & 13.32 & 0.75 \\
\hline 810.0 & 0.0 & 0.207 & 11.83 & 1.13 & 9.50 & 1132.0 & 0.0 & 0.248 & 10.94 & 0.92 & 15.15 & 1496.0 & 0.0 & 0.293 & 13.05 & 13.32 & 0.75 \\
\hline 933.3 & 0.0 & 0.210 & 12.96 & 1.13 & 9.50 & 1340.0 & 0.0 & 0.255 & 15.35 & 0.92 & 15.15 & 1747.0 & 0.0 & 0.300 & 15.14 & 13.32 & 0.75 \\
\hline 1050.0 & 0.0 & 0.211 & 14.02 & 1.13 & 9.50 & 1526.0 & 0.0 & 0.259 & 17.95 & 0.92 & 15.15 & 1975.0 & 0.0 & 0.304 & 18.12 & 13.32 & 0.75 \\
\hline \multicolumn{18}{|c|}{$\Delta_{\mathrm{p}} / \Delta=50 \%$, Earthquake 2} \\
\hline 197.3 & 1297.0 & 0.660 & 22.69 & 1.13 & 9.50 & 212.8 & 1606.0 & 0.691 & 22.94 & 0.92 & 15.15 & 234.8 & 2045.0 & 0.735 & 21.00 & 13.32 & 0.75 \\
\hline 362.2 & 971.7 & 0.627 & 20.32 & 1.13 & 9.50 & 394.5 & 1295.0 & 0.660 & 22.59 & 0.92 & 15.15 & 440.3 & 1753.0 & 0.705 & 18.49 & 13.32 & 0.75 \\
\hline 626.8 & 483.8 & 0.578 & 19.26 & 1.13 & 9.50 & 693.3 & 816.5 & 0.612 & 17.81 & 0.92 & 15.15 & 766.9 & 1185.0 & 0.649 & 17.56 & 13.32 & 0.75 \\
\hline 836.1 & 0.0 & 0.544 & 12.62 & 1.13 & 9.50 & 963.7 & 562.3 & 0.586 & 18.00 & 0.92 & 15.15 & 1031.0 & 785.9 & 0.609 & 17.35 & 13.32 & 0.75 \\
\hline 948.2 & 0.0 & 0.502 & 10.73 & 1.13 & 9.50 & 1205.0 & 361.5 & 0.566 & 17.97 & 0.92 & 15.15 & 1292.0 & 579.2 & 0.548 & 14.00 & 13.32 & 0.75 \\
\hline 1012.0 & 0.0 & 0.467 & 10.42 & 1.13 & 9.50 & 1403.0 & 156.0 & 0.546 & 16.59 & 0.92 & 15.15 & 1532.0 & 414.1 & 0.571 & 13.40 & 13.32 & 0.75 \\
\hline 1052.0 & 0.0 & 0.440 & 12.60 & 1.13 & 9.50 & 1543.0 & 0.0 & 0.522 & 13.75 & 0.92 & 15.15 & 1747.0 & 261.5 & 0.556 & 13.62 & 13.32 & 0.75 \\
\hline 1077.0 & 0.0 & 0.419 & 14.68 & 1.13 & 9.50 & 1639.0 & 0.0 & 0.499 & 15.57 & 0.92 & 15.15 & 1927.0 & 102.2 & 0.540 & 14.56 & 13.32 & 0.75 \\
\hline 1091.0 & 0.0 & 0.401 & 15.56 & 1.13 & 9.50 & 1713.0 & 0.0 & 0.479 & 17.17 & 0.92 & 15.15 & 2058.0 & 0.0 & 0.522 & 16.54 & 13.32 & 0.75 \\
\hline 1097.0 & 0.0 & 0.387 & 15.19 & 1.13 & 9.50 & 1769.0 & 0.0 & 0.462 & 18.74 & 0.92 & 15.15 & 2157.0 & 0.0 & 0.505 & 18.64 & 13.32 & 0.75 \\
\hline 1103.0 & 0.0 & 0.375 & 16.37 & 1.13 & 9.50 & 1811.0 & 0.0 & 0.446 & 20.13 & 0.92 & 15.15 & 2234.0 & 0.0 & 0.488 & 20.79 & 13.32 & 0.75 \\
\hline \multicolumn{18}{|c|}{$\Delta_{\mathrm{p}} / \Delta=80 \%$, Earthquake 2} \\
\hline 128.1 & 1502.0 & 0.680 & 21.60 & 1.13 & 9.50 & 143.7 & 1814.0 & 0.711 & 22.86 & 0.92 & 15.15 & 162.6 & 2192.0 & 0.749 & 22.02 & 13.32 & 0.75 \\
\hline 246.0 & 1400.0 & 0.670 & 21.87 & 1.13 & 9.50 & 277.1 & 1711.0 & 0.701 & 22.91 & 0.92 & 15.15 & 310.2 & 2042.0 & 0.734 & 21.13 & 13.32 & 0.75 \\
\hline 456.8 & 1224.0 & 0.652 & 23.86 & 1.13 & 9.50 & 515.4 & 1517.0 & 0.682 & 22.91 & 0.92 & 15.15 & 566.8 & 1774.0 & 0.707 & 18.31 & 13.32 & 0.75 \\
\hline 638.5 & 1068.0 & 0.639 & 25.20 & 1.13 & 9.50 & 724.9 & 1356.0 & 0.666 & 22.02 & 0.92 & 15.15 & 780.2 & 1541.0 & 0.684 & 18.29 & 13.32 & 0.75 \\
\hline 795.1 & 927.7 & 0.623 & 26.05 & 1.13 & 9.50 & 911.8 & 1220.0 & 0.652 & 22.26 & 0.92 & 15.15 & 968.5 & 1361.0 & 0.666 & 20.12 & 13.32 & 0.75 \\
\hline 934.0 & 807.9 & 0.611 & 25.81 & 1.13 & 9.50 & 1077.0 & 1095.0 & 0.640 & 23.22 & 0.92 & 15.15 & 1144.0 & 1227.0 & 0.653 & 21.79 & 13.32 & 0.75 \\
\hline 1064.0 & 713.5 & 0.601 & 24.36 & 1.13 & 9.50 & 1223.0 & 978.2 & 0.628 & 24.38 & 0.92 & 15.15 & 1299.0 & 1105.0 & 0.641 & 22.85 & 13.32 & 0.75 \\
\hline 1187.0 & 635.4 & 0.594 & 22.02 & 1.13 & 9.50 & 1351.0 & 870.6 & 0.617 & 25.44 & 0.92 & 15.15 & 1437.0 & 993.4 & 0.629 & 22.98 & 13.32 & 0.75 \\
\hline 1299.0 & 563.2 & 0.586 & 21.57 & 1.13 & 9.50 & 1464.0 & 770.5 & 0.607 & 26.01 & 0.92 & 15.15 & 1564.0 & 894.9 & 0.620 & 22.79 & 13.32 & 0.75 \\
\hline 1396.0 & 491.2 & 0.579 & 24.19 & 1.13 & 9.50 & 1565.0 & 679.1 & 0.598 & 26.06 & 0.92 & 15.15 & 1686.0 & 813.8 & 0.611 & 22.53 & 13.32 & 0.75 \\
\hline 1484.0 & 423.6 & 0.572 & 26.37 & 1.13 & 9.50 & 1664.0 & 604.2 & 0.590 & 25.83 & 0.92 & 15.15 & 1812.0 & 752.1 & 0.605 & 22.29 & 13.32 & 0.75 \\
\hline
\end{tabular}

The values highlighted in bold, which are 0 , mean that the pounding force is 0 , so that pounding is not produced.

2. The heavy-weight isolated structures are less responsive to increasing the isolator hysteretic damping than the lightweight ones.

3. Pounding is always more intense in the case of isolated heavy structures, even if they exhibit closer bearing displacements to those of isolated lighter structures.

4. Pounding intensity is directly proportional to the amount of extra base displacement beyond the bearing design displacement.

5. Increasing the isolator hysteretic damping slightly reduces the peak accelerations of the isolated structure.

6. Intense pounding of an isolated structure results in structural accelerations higher than those of its fixed base case. This becomes more obvious in structures with relatively light weight.

7. Increasing the isolator hysteretic damping can remarkably attenuate the undesirable increase of the structural accelerations due to pounding.

8. The RNC isolator can achieve high levels of structural accelerations reduction, especially under severe ground motions.

9. Where there is no pounding, isolation of light-weight structures is less efficient under low-intensity earthquakes compared to heavier structures under the same earthquakes. This isolation efficiency becomes higher under more severe earthquakes showing similar behavior to that of heavier structures under such strong earthquakes.

10. The early incorporation of active control forces to the RNC isolator leads to the best results in terms of avoiding pounding and obtaining structural accelerations lower than those of the fixed-base case using low control forces. On the other hand, the later incorporation of such active control forces cannot lead to satisfactory results even by using much higher values of active control forces.

11. Increasing the control force leads to less efficient seismic isolation as the peak structural acceleration in this case exceeds that of the fixed-base case. This is mainly attributed to the more added rigidity to the isolation system, which certainly decreases the degree of structure-ground decoupling. Such increasing isolator rigidity enables more seismic forces to be transmitted into the isolated structure.

12. Pounding intensity (if any) greatly increases as the structural mass increases.

13. At the same control force, the bearing displacement remarkably increases with the structural mass.

14. Heavier structures are more susceptible to intense pounding forces than lighter structures. 


\section{References}

[1] Kelly M. Aseismic base isolation: review and bibliography. Soil Dyn Earthq Eng 1986;5(4):202-16.

[2] Jangid R, Kelly J. Base isolation for near-fault motions. Earthq Eng Struct Dyn 2001:30:691-707.

[3] Murat D, Srikanth B. Equivalent linear analysis of seismic-isolated bridges subjected to near-fault ground motions with forward rupture directivity effect. Eng Struct 2007;29:21-32.

[4] Zhang W, Xu Y. Vibration analysis of two buildings linked by Maxwell modeldefined fluid dampers. J Sound Vib 2000;233(5):775-96.

[5] Zhu H, Xu Y. Optimum parameters of Maxwell model-defined dampers used to link adjacent structures. J Sound Vib 2005;279:253-74.

[6] Bhaskararao A, Jangid R. Harmonic response of adjacent structures connected with a friction damper. J Sound Vib 2006;292:710-25.

[7] Basili M, De Angelis M. A reduced order model for optimal design of 2-mdof adjacent structures connected by hysteretic dampers. J Sound Vib 2007;306:297-317.

[8] Basili M, De Angelis M. Optimal passive control of adjacent structures interconnected with nonlinear hysteretic devices. J Sound Vib 2007;301:106-25.

[9] Zhu H, Ge D, Huang X. Optimum connecting dampers to reduce the seismic responses of parallel structures. J Sound Vib 2011;330:1931-49.

[10] Tsai H. Dynamic analysis of base-isolated shear beams bumping against stops. Earthq Eng Struct Dyn 1997;26:515-28.

[11] Malhotra P. Dynamics of seismic impacts in base-isolated buildings. Earthq Eng Struct Dyn 1997;26:797-813.

[12] Matsagar V, Jangid R. Seismic response of base-isolated structures during impact with adjacent structures. Eng Struct 2003;25:1311-23.

[13] Agarwal V, Niedzwecki J, van de Lindt J. Earthquake induced pounding in friction varying base isolated buildings. Eng Struct 2007;29(11):2825-32.

[14] Komodromos P, Polycarpou P, Papaloizou L, Phocas M. Response of seismically isolated buildings considering poundings. Earthq Eng Struct Dyn 2007;36:1605-22.

[15] Komodromos P. Simulation of the earthquake-induced pounding of seismically isolated buildings. Comput Struct 2008;86:618-26.

[16] Polycarpou P, Komodromos P. Earthquake-induced poundings of a seismically isolated building with adjacent structures. Eng Struct 2010;32:1937-51.

[17] Ismail M, Rodellar J, Ikhouane F. A seismic isolation system for supported objects. Spanish patent no. P200802043, Spanish Office of Patents and Marks; 2008.

[18] Ismail M, Rodellar J, Ikhouane F. An innovative isolation device for aseismic design. J Eng Struct 2010;32:1168-83.

[19] Ismail M, Rodellar J, Ikhouane F. Seismic protection of low-to moderate- mass buildings using RNC isolator. J Struct Control and Health Monitor 2012;19 (1):22-42.
[20] Ismail M, Rodellar J, Ikhouane F. An innovative isolation bearing for motionsensitive equipment. J Sound Vib 2009;326(3-5):503-21.

[21] Inaudi J, Lopez-Almansa F, Kelly J, Rodellar J. Predictive control of base isolated structures. Earthq Eng Struct Dyn 1992;21(6):471-82.

[22] Subramaniam R, Reinhorn A, Riley M, Nagarajaiah S. Hybrid control of structures using fuzzy logic. Comput-Aided Civ Infrastruct Eng 1996:11:1-17.

[23] Luo N, Rodellar J, De la Sen M, Vehi J. Output feedback sliding mode control of base isolated structures. J Frankl Inst 2000;337:555-77.

[24] Ramallo J, Johnson E, Spencer B. Smart base isolation systems. J Eng Mech 2002;128:1088-100.

[25] Kim H, Roschke P. Fuzzy control of base-isolated system using multi-objective genetic algorithm. Comput-Aided Civ Infrastruct Eng 2006;21:436-49.

[26] Pozo F, Ikhouane F, Pujol G, Rodellar J. Adaptive backstepping control of hysteretic base-isolated structures. J Vib Control 2006;12(4):373-94.

[27] Pozo F, Montserrat P, Rodellar J, Acho L. Robust active control of hysteretic base-isolated structures: application to the benchmark smart base-isolated building. Struct Control Health Monit 2008;15:720-36.

[28] Makris N, Black C. Evaluation of peak ground velocity as a good intensity measure for near-source ground motions. Eng Mech (ASCE) 2004:130 (9):1032-44.

[29] Ismail M. An innovative isolation device for aseismic design [Ph.D. thesis] Doctoral program: Earthquake engineering and structural dynamics. Technical University of Catalunia, Barcelona, Spain; 2009. 〈http://www.tdx.cat/handle 10803/6265 http://hdl.handle.net/10803/6265〉.

[30] Wen Y. Method for random vibration of hysteretic systems. J Eng Mech Div 1976;102(EM2):246-63.

[31] Ismail M, Ikhouane F, Rodellar J. The hysteresis Bouc-Wen model, a survey. J Arch Comput Methods Eng 2009;16:161-88.

[32] Zwillinger D. CRC, standard mathematical tables and formulae. 31st ed.. Boca Raton, FL: CRC Press Inc,; 2003.

[33] Uniform Building Code. In: International conference of building officials California, Whittier; 1997.

[34] AASHTOLRFD Bridge Design Specifications. SI units, 3rd ed. Washington, DC USA: American Association of State Highway and Transportation Officials; 2005. [Interim revisions].

[35] ADINA release 8.73 documentation. ADINA R \& D, Inc., 71 Elton Avenuev Watertown, MA 02472, USA; 2011.

[36] Naeim F, Kelly J. Design of seismic isolated structures - from theory to practice. Hoboken, NJ, USA: John Wiley \& Sons; 1999.

37] SAP2000 release 15.0 documentation. Computers and Structures, Inc., 1995 University Ave, Berkeley, CA 94704; 2011.

[38] The MathWorks, Inc. 3 Apple Hill Drive, Natick, Massachusetts. release R2012a; 2012.

[39] Pozo F, Acho L, Rodellar J. Hyperbolic control for vibration mitigation of a baseisolated benchmark structure. Struct Control Health Monit 2009;16:766-83. 